\title{
ENTRE BACIAS, MALHAS E REDES: DAS METRÓPOLES SEDENTAS À HIDROMEGARREGIÃO
}

\author{
Christian Ricardo Ribeiro* \\ Instituto Doctum de Educação e Tecnologia
}

Resumo: A crise de abastecimento de água ocorrida no biênio 2014-2015 atingiu de forma intensa e prolongada as duas maiores aglomerações metropolitanas brasileiras - Rio de Janeiro e São Paulo -, fortemente dependentes de bacias hidrográficas externas às suas áreas de abrangência e submetidas a um processo histórico de degradação ambiental - Paraíba do Sul e Alto Tietê-PCJ, respectivamente. Para além da ênfase na dimensão natural da conjuntura de crise, expressa na situação de escassez hídrica, o presente trabalho discute o papel desempenhado pelas redes técnicas de infraestrutura na conquista das águas das duas metrópoles, cujos sistemas de abastecimento expandiram-se e articularam-se progressivamente em direção aos mesmos recursos hídricos, por meio de esquemas de transposição que permitem a exploração de mananciais situados a distâncias cada vez maiores. As redes técnicas constituem-se em superfícies de regulação que delimitam e organizam a atuação das companhias estaduais de abastecimento de água, que assumiram o protagonismo da gestão da crise, colocando em xeque os princípios de descentralização e de participação consagrados na Política Nacional de Recursos Hídricos, supostamente expressos na atuação dos Comitês de Bacia Hidrográfica. A decisão do governo paulista, motivada pela crise, de implementar a interligação entre os reservatórios de Jaguari e de Atibainha, com o objetivo de aumentar a segurança hídrica da metrópole paulistana via Sistema Cantareira, acirrou a competição com a metrópole carioca pelo uso dos recursos hídricos do Rio Paraíba do Sul. A interligação significou a possibilidade de conexão física entre esses conjuntos territoriais e evidenciou o processo de construção de uma escala regional de gestão das águas, expressa nos termos de uma "megarregião hídrica", ou de uma "hidromegarregião", circunscrita pela contínua e crescente integração entre os sistemas de abastecimento de água das duas metrópoles.

Palavras-chave: crise de abastecimento de água; escala regional; Hidromegarregião Rio de Janeiro-São Paulo; redes técnicas de infraestrutura; superfícies de regulação.

\section{BETWEEN BASINS, MESHES AND NETWORKS: FROM THE THIRSTY METROPOLES TO THE WATER MEGAREGION}

Abstract: The water supply crisis that occurred in the two-year period of 2014-2015 intensely and protractedly affected the two largest metropolitan agglomerations in Brazil - Rio de Janeiro and São Paulo -, heavily dependent on hydrographic basins outside their catchment areas and subjected to a historical process of environmental degradation - Paraíba do Sul and Alto Tietê-PCJ, respectively. Going beyond emphasis on the natural dimension of the crisis, expressed in the situation of water scarcity, this paper discusses the role played by technical infrastructure networks in conquering the waters of the two metropoles, whose supply systems have been expanded and articulated progressively towards the same water resources, through transposition schemes enabling the exploitation of water sources located at ever greater distances. Technical networks are formed into regulatory areas that delimit and organize the activities of state water supply companies, which have taken on the role of crisis management, placing in check the principles of decentralization and participation enshrined in the National Water Resources Policy, supposedly expressed in the performance of the Hydrographic Basin Committees. The decision by the São Paulo state government, motivated by the crisis, to implement an interconnection between the Jaguari and Atibainha reservoirs, with the aim of increasing the water security in the São Paulo metropolitan area via the Cantareira System, intensified the competition with the Rio de Janeiro metropolitan area for the use of water resources from the Paraiba do Sul River. The interconnection meant the possibility of physical connection between these territorial groups and highlighted the process of building a regional water management scale, expressed in terms of a "water megaregion", or of a "hydromegaregion", circumscribed by the continuous and growing integration between the water supply systems of the two metropoles.

Keywords: water supply crisis; regional scale; Rio de Janeiro-São Paulo Hydromegaregion; technical infrastructure networks; regulatory areas.

\section{ENTRE CUENCAS, MALLAS Y REDES: DE LAS METRÓPOLIS SEDIENTAS A LA MEGARREGIÓN HÍDRICA}

Resumen: La crisis de abastecimiento de agua ocurrida en el bienio 2014-2015 afectó de manera intensa y prolongada las dos aglomeraciones metropolitanas brasileñas más grande - Rio de Janeiro y São Paulo -, fuertemente dependientes de cuencas hidrográficas externas a sus áreas de alcance y sometidas a un proceso histórico de degradación ambiental - Paraíba do Sul y Alto Tietê-PCJ, respectivamente. Además del énfasis en la dimensión natural de la coyuntura de la crisis, expresada en la situación de escasez hídrica, el presente trabajo discute el papel desempeñado por las redes técnicas de infraestructura en la conquista de las aguas de las dos metrópolis, cuyos sistemas de abastecimiento se expandieron y se articularon progresivamente en dirección a los recursos hídricos, mediante esquemas de transposición que permiten la explotación de manantiales ubicados a distancias cada vez mayores. Las redes técnicas se constituyen en superficies de regulación que delimitan y organizan la actuación de las compañías estatales de abastecimiento de agua, que han asumido el protagonismo de la gestión de la crisis, poniendo en jaque los principios de descentralización y de participación consagrados en la Política Nacional de Recursos Hídricos, supuestamente expresados en la actuación de los Comités de Cuenca Hidrográfica. La decisión del gobierno de São Paulo, motivada por la crisis, de implementar la interconexión entre los depósitos de agua de Jaguari y de Atibainha, con el objetivo de aumentar la seguridad hídrica de la metrópolis de São Paulo a través del Sistema Cantareira, provocó la competición con la metrópolis de Rio de Janeiro por el uso de los recursos hídricos del Río Paraíba do Sul. La interconexión significó la posibilidad de conexión física entre estos conjuntos territoriales y evidenció el proceso de construcción de una escala regional de gestión de las aguas, expresa en los términos de una "megarregión hídrica" o de una "hidromegarregión" circunscrita por la continua y creciente integración entre los sistemas de abastecimiento de agua de las dos metrópolis.

Palabras clave: crisis de abastecimiento de agua; escala regional; Hidromegarregión Rio de Janeiro-São Paulo; redes técnicas de infraestructura; superficies de regulación. 
Introdução

A crise de abastecimento de água ocorrida no biênio 2014-2015 reposicionou a temática da gestão das águas na ordem do dia da agenda de discussões de gestores públicos, de pesquisadores, de veículos de comunicação e da sociedade civil organizada ao manifestar-se de uma forma intensa e prolongada sobre as regiões metropolitanas do Rio de Janeiro e de São Paulo. O consumo elevado, que requer a produção de grandes volumes de água tratada para o atendimento das demandas dos diversos usos e dos respectivos usuários, somado à extensão, à integração e ao adensamento das manchas urbanas das cidades que as constituem, implica que o abastecimento hídrico das metrópoles seja comumente estruturado por meio de sistemas integrados, nos quais um conjunto de municípios conurbados compartilha o mesmo sistema de produção de água.

Em algumas situações específicas, as restrições da disponibilidade hídrica local para o atendimento das demandas do abastecimento urbano implicam no reforço da oferta hídrica por meio de transferências de vazões de bacias hidrográficas vizinhas, exigindo a operação de complexos e sofisticados sistemas hidráulicos de transposição de águas cujas áreas de influência projetam-se em uma escala regional. Essa é exatamente a situação vivenciada pelas aglomerações metropolitanas do Rio de Janeiro e de São Paulo, dependentes há décadas de sistemas de transposição de águas.

A transposição de águas da Bacia Hidrográfica do Rio Paraíba do Sul (BHRPS) para a Bacia Hidrográfica do Rio Guandu (BHRG), inaugurada na década de 1950, representa a garantia de abastecimento hídrico de mais de três quatros da população da Região Metropolitana do Rio de Janeiro (RMRJ). Dessa transposição também depende um número expressivo de usuários industriais de grande porte localizados ao longo do Canal de São Francisco (COHIDRO, 2014; SONDOTÉCNICA, 2006). Da mesma forma, ainda que a maior parte da área de abrangência da Região Metropolitana de São Paulo (RMSP) se localize na Bacia Hidrográfica do Alto Tietê (BHAT), cerca de metade da sua população é abastecida pelas águas transpostas das Bacias Hidrográficas dos Rios Piracicaba, Capivari e Jundiaí (Bacias PCJ), por meio do Sistema Cantareira, inaugurado na década de 1970 (COBRAPE, 2010; FUSP, 2009).

As tensões, as disputas e os conflitos que emergiram ou se acirraram em decorrência da conjuntura de escassez hídrica manifestaram-se para além dos limites político-administrativos dos municípios que constituem essas regiões metropolitanas e dos limites naturais das bacias hidrográficas em que se localizam, evidenciando a forte dependência de áreas externas que garantem o abastecimento de água, sob a mediação das redes técnicas de infraestrutura. Postulamos que a manifestação da crise tornou visível a ruptura com a abordagem da gestão das águas preconizada pela Política Nacional de Recursos Hídricos (PNRH), instituída pela Lei Federal n.o 9.433, de 08 de janeiro de 1997. A despeito de a descentralização e a participação terem sido consagradas pela Lei das Águas como fundamentos basilares para a organização e o funcionamento do Sistema Nacional de Gerenciamento de Recursos Hídricos (SINGREH), expressos na atuação dos Comitês de Bacia Hidrográfica (CBHs), estes órgãos colegiados de composição tripartite - poder público, usuários e sociedade civil - restringiram a sua atuação durante a crise à função de assessoramento dos órgãos gestores de recursos hídricos por meio da elaboração de estudos e de relatórios técnicos.

Paralelamente à atuação dos $\mathrm{CBHs}$, as redes técnicas de infraestrutura de abastecimento de água expandiram-se, densificaram-se e integraramse contínua e progressivamente, impulsionadas pela crescente pressão decorrente do aumento da demanda hídrica, permitindo a exploração de recursos hídricos de mananciais situados a distâncias cada vez maiores dos centros consumidores. A crise evidenciou as tensões e as disputas estabelecidas nas zonas de contato e/ ou de interseção entre as diferentes "superfícies de regulação" (PIRES DO RIO e PEIXOTO, 2001) - bacia hidrográfica, malha político-administrativa e rede técnica - intervenientes na gestão dos recursos hídricos que abastecem as regiões metropolitanas do Rio de Janeiro e de São Paulo.

Nesse contexto, a tese sustentada por este trabalho é a de que a crise de 2014-2015 evidenciou a associação entre a organização institucional proposta pela PNRH, que tem nos $\mathrm{CBH}$ s a instância própria de descentralização e na bacia hidrográfica a referência territorial dos atores do SINGREH, e os sistemas técnicos de infraestrutura de abastecimento de água, que constituem a referência territorial dos atores que disputam a apropriação e o controle dos recursos hídricos compartilhados pelas regiões metropolitanas do Rio de Janeiro e de São Paulo, projetando a gestão das águas na escala regional, expressa territorialmente na emergência de uma megarregião hídrica.

Os caminhos da análise

A tese que orienta o desenvolvimento deste trabalho 
será desenvolvida e sustentada a partir da aplicação do conceito de superfície de regulação. Definidas como "a expressão espacial das especificidades institucionais que atuam na regulação das atividades econômicas" (PIRES DO RIO, 2009, p. 29), as superfícies de regulação estão apoiadas em malhas específicas que definem as condições de acesso e de uso, para os diferentes atores interessados, dos recursos por elas abrangidos e/ou dos serviços associados - no caso em questão, os recursos hídricos dos mananciais destinados ao aprovisionamento das regiões metropolitanas do Rio de Janeiro e de São Paulo e os serviços de abastecimento de água operados e controlados pelas companhias estaduais.
A crise evidenciou as superfícies de regulação intervenientes na gestão das águas que abastecem a RMRJ e a RMSP. Essas superfícies - malha políticoadministrativa, bacia hidrográfica e rede técnica de infraestrutura - se sobrepõem no território (Figura 1) e circunscrevem os espaços de atuação de órgãos e de entidades que compõem um amplo e diversificado mosaico de atores - reconhecido como densidade institucional, nos termos propostos por Amin e Thrift (1993) - que intervêm, em diferentes formas e intensidades, nesse processo de gestão em diferentes escalas geográficas.

Figura 1 - Superfícies de regulação intervenientes na gestão de recursos hídricos no Brasil: superposição de limites.

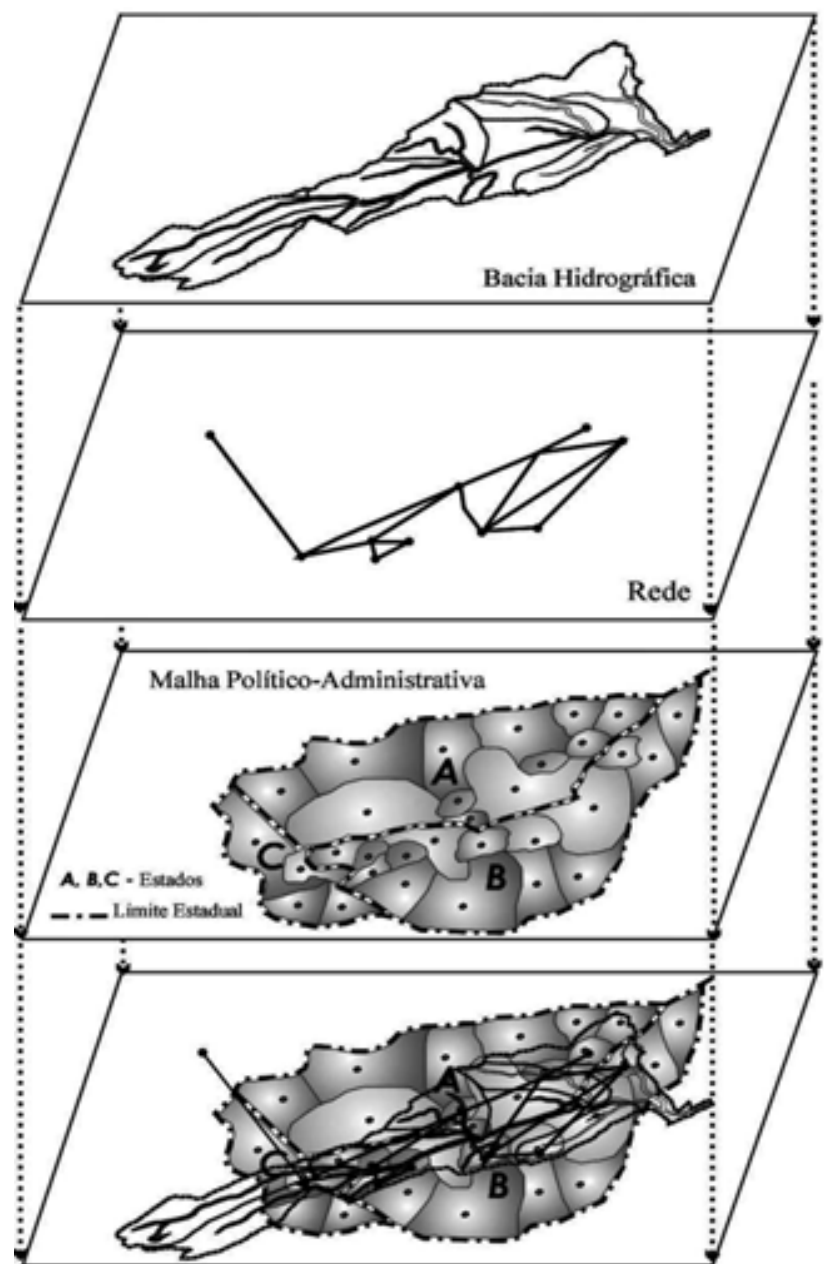

Fonte: Pires do Rio e Peixoto (2001, p. 63)

A partir disso, algumas questões essenciais orientaram o desenvolvimento do trabalho. Quais são as superfícies de regulação intervenientes na gestão das águas que abastecem a RMRJ e a RMSP? Quais são os atores vinculados a cada uma dessas superfícies? Como a associação/superposição/interseção entre essas diferentes superfícies e as relações estabelecidas entre os atores a elas vinculados durante a crise de 2014-2015 projetaram a gestão das águas em uma escala regional, expressa na constituição e na emergência de uma megarregião hídrica ou de uma hidromegarregião?

Para responder a essas questões, o percurso metodológico delineado consistiu, em um primeiro momento, no mapeamento das superfícies de regulação, recorrendo-se à cartografia temática, que se constitui em uma ferramenta importante nas análises multiescalares dos sistemas de gestão das águas. A elaboração dos mapas demandou um conjunto expressivo de dados 
e de informações, disponibilizados nos bancos de dados geográficos de órgãos e de entidades como a Agência Nacional de Águas (ANA), o Comitê das Bacias Hidrográficas dos Rios Guandu, da Guarda e Guandu-Mirim (CBH-Guandu), o Comitê de Integração do Rio Paraíba do Sul (CEIVAP), o Greenpeace, o Instituto Brasileiro de Geografia e Estatística (IBGE), o Ministério do Meio Ambiente (MMA) e a Secretaria de Estado de Meio Ambiente de São Paulo (SMA).

Em um segundo momento, procedeu-se à identificação dos atores da gestão das águas vinculados às três categorias de superfícies de regulação - malha político-administrativa, bacia hidrográfica e rede técnica de infraestrutura. Finalmente, analisou-se a constituição e a emergência de uma nova espacialidade, expressa na forma de uma megarregião hídrica, a partir da associação/superposição/interseção entre essas diferentes superfícies de regulação e das relações estabelecidas entre os atores a elas vinculados no contexto da gestão da crise de abastecimento ocorrida em 2014-2015.

A operacionalização dessas etapas da pesquisa se deu através da consulta a um vasto conjunto de documentos oficiais, incluindo: planos estaduais de recursos hídricos; planos de bacia, planos de recursos hídricos, relatórios e estudos técnicos disponibilizados pelos $\mathrm{CBHs}$; planos setoriais de contingência e de emergência; atas de reuniões ordinárias e extraordinárias plenárias de órgãos colegiados; e deliberações, resoluções, portarias e moções emitidas por órgãos colegiados e por órgãos gestores de recursos hídricos no contexto da crise. Esses documentos foram disponibilizados pelos seguintes órgãos: Agência Nacional de Águas (ANA), Centro Estadual de Estatísticas, Pesquisas e Formação de Servidores Públicos do Rio de Janeiro (CEPERJ), Instituto Brasileiro de Geografia e Estatística (IBGE), Instituto de Pesquisa Econômica Aplicada (IPEA) e Sistema Estadual de Análise de Dados de São Paulo (SEADE).

Rio de Janeiro: concentração metropolitana e dependência hídrica

A Região Metropolitana do Rio de Janeiro (RMRJ), originalmente composta por 14 municípios, foi estabelecida pela Lei Complementar Federal n.o 20, de 01.0 de julho de 1974. Desde então, vários municípios foram incorporados, excluídos e/ou reincorporados à RMRJ, compreendendo atualmente 21 municípios, que ocupam uma área total de $6.735,954 \mathrm{~km} 2$. Constitui uma das oito Regiões de Governo do Estado do Rio de Janeiro, cujos limites resultam do agrupamento dos municípios fluminenses segundo os critérios e os objetivos definidos no Plano de Desenvolvimento Econômico e Social 19881991, aprovado pela Lei Estadual n.o 1.227, de 17 de novembro de 1987. A RMRJ abrigava uma população total de 11.945 .532 habitantes e uma população urbana de 11.865.700 habitantes em 2010, o que a torna a segunda maior aglomeração metropolitana brasileira, ficando atrás apenas da metrópole paulistana (IBGE, 2010).

A tendência de concentração demográfica e econômica em relação ao restante do atual Estado do Rio de Janeiro (DAVIDOVICH, 2001) é uma das características mais notáveis da metrópole carioca em todas as fases históricas de seu desenvolvimento. 0 gigantismo do município central da RMRJ mantém os municípios conurbados em um nível de periferia pouco valorizada, o que resulta na redução dos investimentos nessas áreas e na sobrecarga das funções administrativas e na hiperconcentração dos serviços na capital (SILVA, 2016). A década de 2000 caracterizou-se pela emergência de novas pressões sobre o território, que resultaram de um conjunto de iniciativas fomentadas e/ou conduzidas pelo setor produtivo, sobre as quais o governo estadual não exerceu uma influência significativa, tanto no planejamento como na regulação (GUSMÃo, 2009). Essas pressões também se impuseram sobre os já então saturados sistemas de abastecimento de água que atendem a metrópole carioca e a sua região metropolitana.

Segundo a divisão hidrográfica do Estado do Rio de Janeiro, instituída pela Resolução CERHI-RJ n.o 107, de 22 de maio de 2013, a quase totalidade da área de abrangência da RMRJ distribui-se pela área de drenagem de duas Regiões Hidrográficas (RHs): Guandu (RH-II) e Baía de Guanabara $(\mathrm{RH}-\mathrm{V})$. O consumo de água e a demanda hídrica na RMRJ têm uma relação direta com o quadro de concentração demográfica e econômica e com a evolução da cobertura da rede de abastecimento nessas duas RHs.

A RH-Guandu, com 1.631.056 habitantes, e a RHGuanabara, com 10.328.593 habitantes, eram as mais populosas do Estado do Rio de Janeiro no ano de 2010, devendo manter-se nessa condição, segundo as projeções realizadas no Relatório de Cenário Demográfico e Econômico do Plano Estadual de Recursos Hídricos do Estado do Rio de Janeiro (PERHI-RJ), até o ano de 2030, quando contarão com populações de $2.024 .273 \mathrm{e}$ de 12.870.387 de habitantes, respectivamente. A RH-V responde, segundo o relatório publicado em 2013, por 
$66,8 \%$ da população urbana, por $62,0 \%$ do PIB e por aproximadamente $70 \%$ da demanda hídrica do setor de abastecimento humano do Estado do Rio de Janeiro. Já a RH-II caracteriza-se pela expressiva concentração da atividade industrial, respondendo por $50 \%$ da demanda hídrica do setor no estado.

A análise da posição geográfica das redes técnicas de infraestrutura que compõem os sistemas de abastecimento de água da RMRJ sugere o agrupamento dos municípios metropolitanos em dois setores (CASTRO, 2010). O setor oeste corresponde a uma área densamente urbanizada e de forte concentração demográfica e econômica, cujos municípios são abastecidos por três sistemas que se complementam e, assim, constituem o Sistema Integrado Metropolitano de Abastecimento de Água Guandu-Lajes-Acari. Esse sistema apresenta uma vazão total de $49,4 \mathrm{~m} 3 / \mathrm{s}$, dos quais $42,0 \mathrm{~m} 3 / \mathrm{s}$ provêm da Estação de Tratamento de Água do Guandu (ETA Guandu), sendo o responsável pelo atendimento de uma população estimada em 8.629.039 habitantes em 2010, equivalente a $89,35 \%$ da população urbana das sedes municipais abastecidas (COPPETEC, 2014).

O cenário tendencial do PERHI-RJ indica que a demanda hídrica do setor de abastecimento urbano na RMRJ deverá crescer de 58.165,70 L/s, em 2010, para $80.143,15 \mathrm{~L} / \mathrm{s}$, em 2030. A maior parte dessa demanda (85,8\% em 2010) refere-se aos 12 municípios abastecidos pelo sistema integrado. Os municípios de Belford Roxo, Duque de Caxias, Japeri, Nilópolis, São João de Meriti, Nova Iguaçu, Queimados e Mesquita, além de parte do Município do Rio de Janeiro, são abastecidos pelo Sistema Guandu. Já os municípios de Paracambi, Seropédica, Queimados, Japeri, Nova Iguaçu e Itaguaí, além de parte do Município do Rio de Janeiro, são abastecidos pelo Sistema Lajes. O Sistema Acari abastece os municípios de Nova Iguaçu e Duque de Caxias, chegando, no máximo, a abastecer algumas áreas do Município de Belford Roxo.

O outro setor da RMRJ, o leste, é abastecido desde o final de 1999 pelo Sistema Imunana-Laranjal, que cobre os municípios de Niterói, São Gonçalo e Itaboraí, além da Ilha de Paquetá, em uma região sujeita a crescentes pressões em termos de demanda por água devido a um expressivo conjunto de investimentos produtivos em implementação, especialmente o Complexo Petroquímico do Estado do Rio de Janeiro (COMPERJ). A população atendida foi estimada em 1.514 .756 de habitantes em 2010 , equivalente a $89,0 \%$ da população urbana das sedes municipais abastecidas (COPPETEC, 2014).
Longe de ser um mero acaso, "a opção pela organização do abastecimento metropolitano nesses dois macrossistemas se fez junto com a fusão dos estados do Rio de Janeiro e Guanabara e com a criação da CEDAE" (BRITTO, 2015, p. 488). Desde então, o Sistema Guandu, projetado na década de 1950 para atender à demanda do antigo Estado da Guanabara, vem sendo progressivamente ampliado em termos de capacidade de produção de água e de implantação de novas linhas de adução e de redes de distribuição para atender à região da Baixada Fluminense. O Mapa 1 apresenta a distribuição espacial desses sistemas nas unidades hidrográficas que drenam a RMRJ.

A superfície de regulação representada pela rede técnica de infraestrutura circunscreve as escalas nas quais atuam os agentes responsáveis pela operação dos serviços de abastecimento de água na RMRJ. A Companhia Estadual de Águas e Esgotos (CEDAE) é a responsável pela prestação desses serviços em 64 municípios do Estado do Rio de Janeiro. Produz água tratada para 20 municípios da RMRJ, de modo

que a quase totalidade de seus habitantes depende da CEDAE para o seu abastecimento, tanto na área de influência do Sistema Integrado Acari-Guandu-Lajes (porção oeste), dependente de uma transposição, como na área de influência do Sistema Imunana-Laranjal (porção leste). Assim, uma das principais decorrências da transposição Paraíba do Sul-Guandu é que "a escala da gestão foi condicionada pela competência atribuída respectivamente às duas empresas (Light e CEDAE), com predomínio da companhia de eletricidade no controle da afluência da água" (PIRES DO RIO, 2008, p. 233).

0 Sistema Acari-Guandu-Lajes integra-se ao Complexo Hidroelétrico de Ribeirão das Lajes, por meio do qual são desviadas e conduzidas as vazões que alimentam a Calha da CEDAE e a ETA Guandu. Esse complexo, por sua vez, opera de uma forma integrada ao Complexo Hidroelétrico de Paraíba do Sul-Lajes, composto pelas usinas hidroelétricas (UHEs) e pelos reservatórios de regularização das águas do Rio Paraíba do Sul situados nos estados do Rio de Janeiro e de São Paulo (Mapa 2). A operação está a cargo de um conjunto de concessionárias do setor de energia elétrica (Light, CESP e FURNAS), sob a coordenação e o controle do Operador Nacional do Setor Elétrico (ONS), que exerce essas atribuições sobre as instalações de geração e de transmissão de energia elétrica que integram o Sistema Interligado Nacional (SIN). A fiscalização e a regulação do ONS estão a cargo da Agência Nacional de Energia Elétrica (ANEEL). 


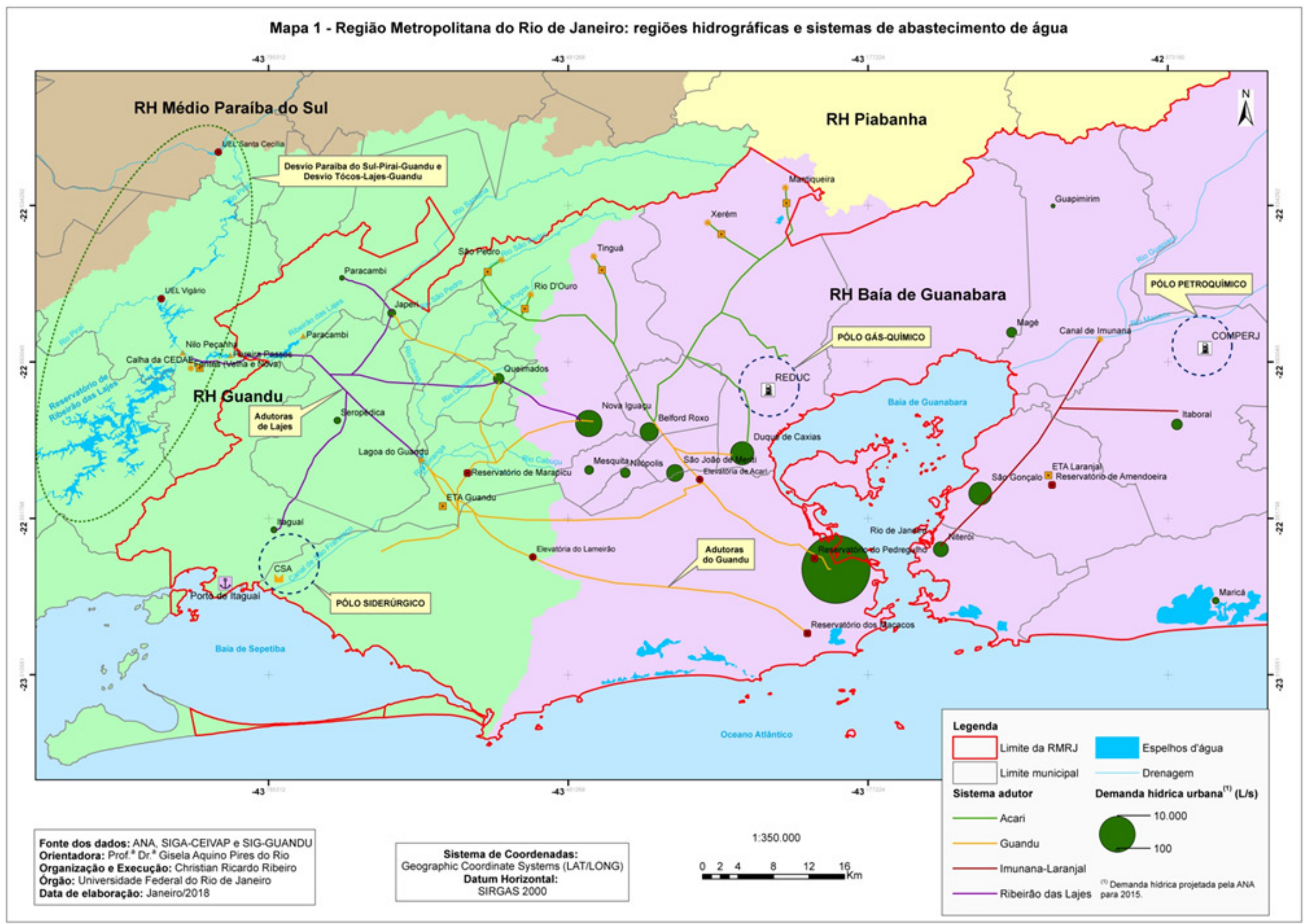




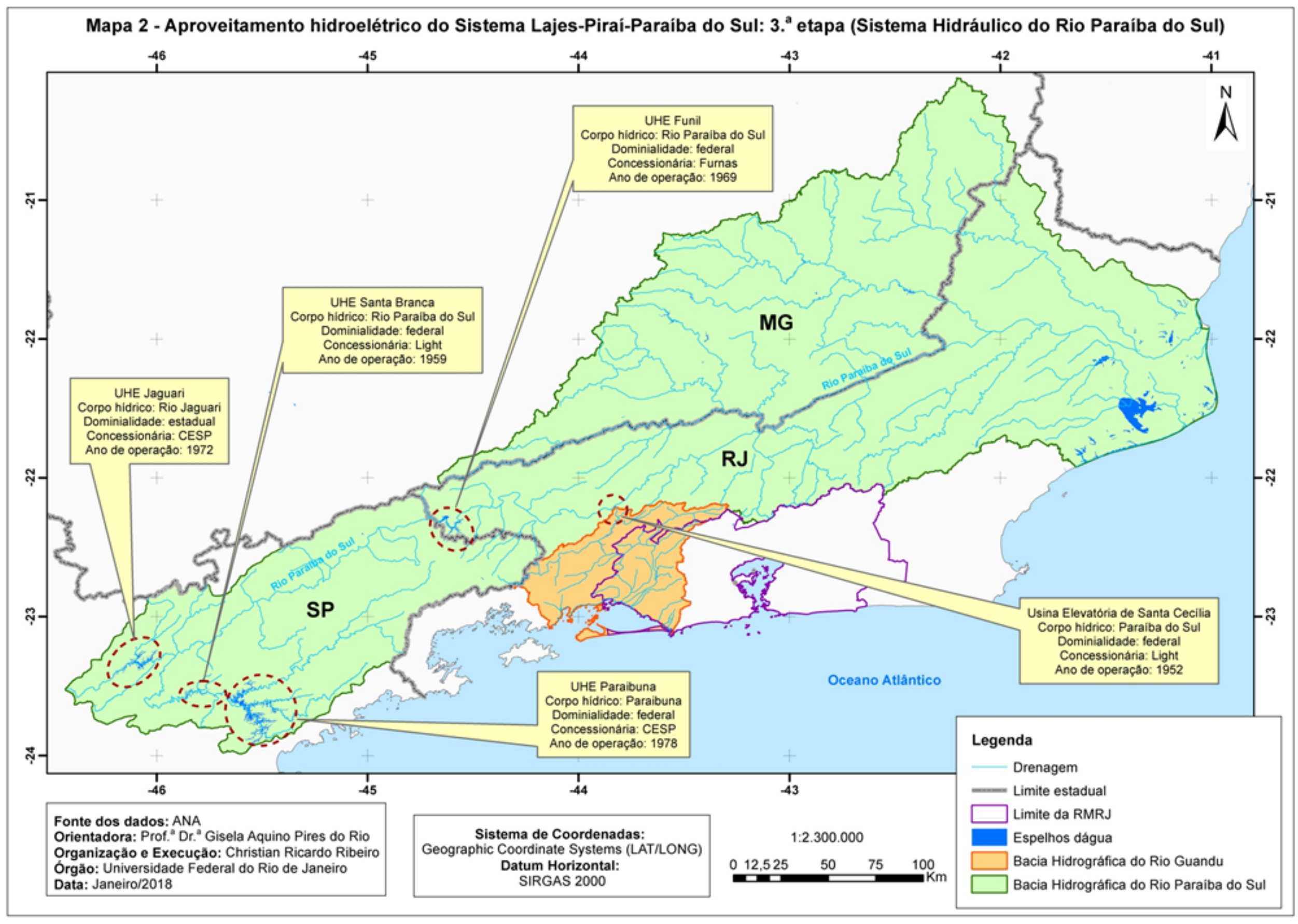


Existe uma profunda relação de interdependência estabelecida entre o fato metropolitano e os sistemas técnicos de infraestrutura de abastecimento de água. Essa relação é evidenciada pelo Mapa 1, que apresenta as demandas hídricas municipais, que refletem, por sua vez, a distribuição da população e das áreas urbanizadas dos municípios da RMRJ; a distribuição espacial dos sistemas de abastecimento de água nas unidades hidrográficas que drenam a RMRJ; e a localização dos pólos de investimentos produtivos que implicam no aumento da pressão sobre o abastecimento e influem na direção a ser tomada pelos fluxos de água no interior do espaço metropolitano.

Os investimentos realizados possibilitaram a implantação de um conjunto de empreendimentos que, sob a responsabilidade da Petrobras, da Companhia Siderúrgica Nacional (CSN) e da Vale S.A., deram origem a três grandes complexos industriais, conforme aponta Gusmão (2009): siderúrgico, petroquímico e gásquímico. De um lado, ressalta o autor, consolidaram-se no entorno da Baía de Guanabara, na porção centro-leste do aglomerado metropolitano, dois complexos formados por unidades de processamento integradas à produção de óleo e de gás realizada na Bacia de Campos: i) a implementação do Plano de Antecipação da Produção de Gás (PLANGÁS), a

consolidação do Pólo Gás-Químico e a ampliação da Refinaria Duque de Caxias (REDUC); e ii) o Complexo Petroquímico do Rio de Janeiro (COMPERJ).

Do outro lado, prossegue o referido autor, consolidouse um complexo siderúrgico situado às margens da Baía de Sepetiba, nas proximidades do Porto de Itaguaí, com a ampliação da Cosigua, do Grupo Gerdau, a mais antiga das usinas instaladas na região. Além disso, o pólo foi fortalecido pela construção de duas outras usinas. A primeira é a Companhia Siderúrgica do Atlântico (CSA), controlada pelo Grupo ThyssenKrupp e com a participação societária da Companhia Vale S.A.. A planta, localizada no Distrito Industrial de Santa Cruz, no Município do Rio de Janeiro, entrou em operação em junho de 2010. A segunda é a Usina Siderúrgica de Itaguaí (USITA), de propriedade da Companhia Siderúrgica Nacional (CSN), localizada no Município de Itaguaí.

Esses três pólos são interconectados pelo Arco Metropolitano do Rio de Janeiro (Rodovia Raphael de Almeida Magalhães), uma nova denominação atribuída à RJ-109, cuja duplicação era prevista em projetos formulados na década 1970. 0 arco tem uma extensão total de $145 \mathrm{~km}$, interligando a porção oeste da RMRJ, na bacia drenante à Baía de Sepetiba, onde se localiza o pólo siderúrgico (Município de Itaguaí), à sua porção leste, na bacia drenante à Baía de Guanabara, onde se localiza o pólo petroquímico (Município de Itaboraí). 0 arco também corta a Baixada Fluminense, na porção central da RMRJ, onde se localiza o pólo gás-químico (Município de Duque de Caxias), podendo ser integrado à RJ-114 até o Município de Maricá, delimitando os espaços de competição pelo uso da água na metrópole carioca.

A CEDAE está implementando atualmente um conjunto de obras de ampliação e de modernização dos sistemas de produção, de adução, de reservação e de distribuição de água da RMRJ. Às redes técnicas já existentes, que compreendem as adutoras que interligam as áreas produtoras (Sistema Acari-Guandu-Lajes) às áreas consumidoras (capital e Baixada Fluminense) de água, percorrendo vários municípios metropolitanos, deverão somar-se novas captações, adutoras e redes de distribuição, implementadas com o objetivo de garantir o atendimento da demanda hídrica futura da RMRJ.

O Sistema Guandu importa aproximadamente dois terços da vazão do Rio Paraíba do Sul, o que lhe confere uma disponibilidade hídrica e uma reserva legal de água suficientes para a realização de ampliações futuras, além de uma elevada capacidade de reservação graças aos quatro grandes reservatórios implantados neste rio. Por

outro lado, a forte dependência em relação a um único manancial, conforme mostra a Tabela 1, constituise em um importante fator de vulnerabilidade, além de demandar, em decorrência da transposição, uma gestão compartilhada e, portanto, mais complexa.

\begin{tabular}{l|c|c}
\hline \multicolumn{2}{c}{ Tabela 1 - População abastecida pela Bacia Hidrográfica do Rio Paraíba do Sul } \\
\hline \multicolumn{2}{c}{ Estados } & População abastecida \\
\hline São Paulo & \multirow{2}{*}{ Bacia Hidrográfica do Rio Paraíba do Sul } & 3.797 .930 \\
\cline { 1 - 2 } Minas Gerais & & 1.490 .274 \\
\cline { 1 - 2 } Rio de Janeiro & Região Metropolitana do Rio de Janeiro (transposição) & 2.898 .690 \\
\cline { 2 - 3 } & Total & $\mathbf{1 7 . 6 3 4 . 3 0 1}$ \\
\hline \multicolumn{2}{c}{ Estado do Rio de Janeiro } & População abastecida \\
\hline \multicolumn{2}{c}{ População abastecida pelo Rio Paraiba do Sul } & 12.346 .097 \\
\hline População total do estado & 16.369 .179 \\
\hline Percentual da população do estado abastecida pelo Rio Paraíba do Sul & $\mathbf{7 5} \%$ \\
\hline
\end{tabular}

Fonte: Nota Técnica DIGAT/INEA n. ${ }^{\circ} 01-\mathrm{A}$, de 26 de março de 2014. 
As alternativas de expansão do sistema de abastecimento de água da porção oeste da RMRJ são bastante limitadas, contando basicamente com o próprio Rio Guandu. O Sistema Lajes é limitado pela capacidade da Calha da CEDAE e, principalmente, pelas restrições da capacidade de acumulação do Reservatório de Lajes, ao passo que o Sistema Acari já opera em sua capacidade máxima (BRITTO, FORMIGA-JOHNSSON e CARNEIRO, 2015). A principal obra prevista pela CEDAE para a expansão da capacidade de atendimento do Sistema Guandu é a construção da ETA Novo Guandu. A ETA terá uma capacidade total de 36.000 L/s e será implantada de forma progressiva, em três módulos, cada um com capacidade de 12.000 L/s. A obra tem o objetivo de aumentar a oferta de água para a Baixada Fluminense, reduzindo o déficit histórico dos índices de abastecimento nessa área, além de proporcionar uma maior segurança ao atual sistema produtor de água tratada, servindo como uma alternativa em situações de risco ou de necessidade de manutenção da ETA existente atualmente (ETA Guandu).

O Sistema Imunana-Laranjal apresenta uma situação mais crítica, o que se explica por um conjunto de variáveis internas e externas ao sistema (BRITTO, FORMIGA-JOHNSSON e CARNEIRO, 2015). O sistema apresenta um baixo nível de regularização de seus principais rios (Guapiaçu e Macacu) e uma limitada capacidade de reservação, estando mais exposto às variações hidrológicas, especialmente em um contexto de recorrência de episódios de estiagens prolongadas nos últimos anos. Soma-se a isso a limitação da ETA Laranjal, cuja capacidade máxima de tratamento é igual à vazão afluente $(7.000 \mathrm{~L} / \mathrm{s})$, operando em déficit em relação à demanda desde 2010 .

Entre as alternativas consideradas para a expansão do sistema está a construção de uma barragem no Rio Guapiaçu, que possibilitaria um incremento de vazões entre 4.000 e 5.000 L/s e cobriria o déficit existente na porção leste (BARCELOS et al., 2014). Outra possibilidade seria, conforme ressalta Castro (2010), uma articulação com a ampliação da ETA Guandu, elevando ainda mais o nível de integração do abastecimento de água na RMRJ, reservando as vazões do Sistema Imunana-Laranjal para o atendimento dos municípios de Niterói e Itaboraí e da Ilha de Paquetá e transferindo o suprimento de São Gonçalo para o Sistema Guandu. Essa alternativa demandaria a construção de uma adutora passando pelo atual "vazio de rede" existente nos municípios de Duque de Caxias, Magé e Guapimirim, não asseguraria o fornecimento de água para os habitantes desses municípios e tensionaria ainda mais as outorgas e o abastecimento urbano no setor oeste da metrópole, revelando como "a articulação em rede implica em distorções na gestão que se pretende por bacias, já que - COMPERJ seria um usuário das águas do Guandu, fora dos limites desta bacia" (CASTRO, 2010, p. 90).

As limitações impostas pelo lançamento de esgotos domésticos e de efluentes industriais, reduzindo a disponibilidade hídrica em termos qualitativos no Rio Guandu, também representam um sério agravante para o cenário futuro do abastecimento de água na RMRJ (SILVA, OLIVEIRA e CONSOLI, 2009). Finalmente, devese ressaltar que a possibilidade de implementação de arranjos alternativos para o abastecimento da RMSP, incluindo as novas transposições de água, poderia resultar no aumento da pressão sobre a RMRJ, em decorrência de sua forte dependência hídrica do Rio Paraíba do Sul e de um contexto de maior frequência e severidade de episódios de seca.

\section{São Paulo: expansão metropolitana e integração hídrica}

A Região Metropolitana de São Paulo (RMSP) foi originalmente instituída pela Lei Complementar Federal n.o 14, de 08 de junho de 1973. Com a promulgação de um novo texto constitucional, em 1988, que atribuiu aos estados a responsabilidade de, "mediante lei complementar, instituir regiões metropolitanas, aglomerações urbanas e microrregiões, constituídas por agrupamentos de municípios limítrofes, para integrar a organização, o planejamento e a execução de funções públicas de interesse comum" (Artigo 25, § 3.o), a existência legal e política da RMSP ficou condicionada à aprovação de uma legislação estadual específica. Essa lacuna foi preenchida pela Lei Complementar Estadual n.o 1.139, de 16 de junho de 2011, que reorganiza a RMSP e cria o seu respectivo Conselho de Desenvolvimento. A RMSP é composta atualmente por 39 municípios, ocupando uma área total de 7.946,956 km2. Abrigava uma população total de 19.683 .975 habitantes e uma população urbana de 19.458.888 habitantes em 2010, sendo a maior aglomeração metropolitana brasileira (IBGE, 2010).

O processo de metropolização no Estado de São Paulo constitui-se como o eixo norteador de uma recente "metamorfose metropolitana", caracterizando uma fase superior da urbanização (LENCIONI, 2011). Os processos de metropolização e de desconcentração industrial estão intrinsecamente relacionados, o que se expressa pela expansão e pela intensificação da industrialização no entorno metropolitano, ao mesmo tempo em que se reafirma a primazia do núcleo metropolitano, a Cidade de São Paulo, como o centro, por excelência, da gestão do capital. 0 complexo industrial, apesar de adjetivado 
como "metropolitano", transpassa em muitos os limites político-administrativos dos municípios que compõem a RMSP, resultando na emergência de uma nova realidade metropolitana, "mais expandida e conectada com espaços para além da região metropolitana em si" (RIBEIRO, SILVA e RODRIGUES, 2011, p. 190).

Em âmbito governamental, a Empresa Paulista de Planejamento Metropolitano (EMPLASA) tem traduzido esse novo fato urbano de caráter intermetropolitano no Estado de São Paulo com a expressão "Macrometrópole Paulista" (MMP). A macrometrópole constitui-se em um sistema integrado e hierarquizado, composto por um total de 174 municípios, em um raio aproximado de 150 a $200 \mathrm{~km}$ de distância a partir do Município de São Paulo, o seu núcleo principal. É composta por um conjunto de unidades regionais institucionalizadas pelo governo estadual, incluindo aglomerações urbanas metropolitanas, aglomerações urbanas não metropolitanas e microrregiões, polarizadas por centros urbanos articulados em rede. Ocupa cerca de $50 \%$ da área urbanizada estadual, apresenta um elevado grau de urbanização em todas as unidades regionais e abrigava um total de 30.703.973 habitantes em 2010 (EMPLASA, 2015).

Cerca de $70 \%$ da área de abrangência da RMSP, incluindo 34 de seus municípios, localizam-se na área drenada pela Bacia Hidrográfica do Alto Tietê. A Unidade de Gerenciamento de Recursos Hídricos (UGRHI) Alto Tietê, a UGRHI 6, integra a divisão hidrográfica do Estado de São Paulo, instituída pela Lei Estadual n.o 16.337, de 14 de dezembro de 2016. A BHAT é uma bacia de cabeceira, com uma vazão média de "apenas" 90 m3/s e definida pela área drenada pelo Rio Tietê e seus afluentes, desde as nascentes até a Barragem de Pirapora, situada no Município de Pirapora de Bom Jesus.

A BHAT também é a receptora das águas transpostas de duas UGRHIs contíguas a ela: Piracicaba/Capivari/ Jundiaí, que transfere as suas águas para a RMSP por meio do Sistema Cantareira, e Ribeira de Iguape/Litoral Sul, por meio do Sistema São Lourenço, evidenciando a crescente conexão hídrica existente entre as unidades regionais que compõem a MMP (SILVA, 2011 e 2015). 0 imperativo de enfrentar as demandas conjuntas dessas unidades por meio de políticas integradas foi reconhecido pelo governo paulista no Plano de Ação da Macrometrópole Paulista (2013-2040). Com o intuito de se adequar à realidade de crescente complexidade territorial e funcional, o Decreto Estadual n.o 52.748, de 26 de fevereiro de 2008, instituiu um Grupo de Trabalho encarregado de estabelecer as bases e as diretrizes do edital de elaboração do Plano Diretor de Aproveitamento de Recursos Hídricos para a Macrometrópole Paulista
(PDARH-MMP), que deveria constituir-se no principal referencial para o planejamento integrado do aproveitamento hídrico na área de abrangência da MMP.

O PDARH-MMP projetou uma população de 37.021.683 habitantes para a macrometrópole em 2035, com destaque para as UGRHIs 05 (PCJ) e 06 (Alto Tietê), que deverão responder por 16,8\% (6.217.851 habitantes) e por $62,0 \%$ (22.938.472 habitantes), respectivamente, deste total. A UGRHI 06 concentrava em 2008 a maior parcela da demanda hídrica do abastecimento urbano e da indústria, que correspondiam a $63,4 \%$ e a $53,6 \%$, respectivamente, da demanda total desses setores na MMP. A RMSP também respondia por $49,9 \%$ da demanda hídrica total da MMP nesse mesmo ano. 0 plano também estimou a necessidade adicional de $60,11 \mathrm{~m} 3 / \mathrm{s}$ de água, no cenário tendencial - projeção das tendências atuais (2008) de crescimento demográfico e da atividade econômica - para atender a uma demanda hídrica total igual a $283,07 \mathrm{~m}^{3} / \mathrm{s}$ em 2035 , equivalente ao dobro da capacidade de produção do Sistema Cantareira e a quatro vezes a capacidade do Sistema Guarapiranga em 2008 (COBRAPE, 2013).

$\mathrm{Na}$ BHAT, que apresenta um quadro crítico de poluição das águas (FRACALANZA e CAMPOS, 2006), estão localizados os mananciais de sete dos nove sistemas integrados de abastecimento de água da RMSP. O Sistema Integrado de Abastecimento de Água da RMSP é composto por nove subsistemas produtores: Alto Cotia, Alto Tietê, Baixo Cotia, Cantareira, Guarapiranga, Ribeirão da Estiva, Rio Claro, Rio Grande e São Lourenço. Juntos, constituem um intrincado e complexo sistema, de grandes proporções, concebido para garantir o abastecimento de água de quase 20 milhões de pessoas, na região de maior concentração industrial do país. 0 Mapa 3 apresenta a distribuição espacial dos sistemas produtores de água da RMSP.

O Sistema Cantareira é o maior dos sistemas de abastecimento de água da RMSP, responsável pelo atendimento de cerca de metade de sua população. Esse foi o sistema mais atingido pela crise de 2014-2015: o volume útil de seus reservatórios foi completamente esgotado, levando a companhia de saneamento responsável pela operação, a SABESP, a utilizar as respectivas reservas técnicas ("volume morto") para evitar o colapso generalizado do abastecimento. Em condições de normalidade hidrológica, o sistema tem condições de abastecer um total de 8,8 milhões de pessoas nos municípios de Barueri, Caieiras, Cajamar, Carapicuíba, Francisco Morato, Franco da Rocha, Guarulhos, Osasco, Santo André, São Caetano do Sul, São Paulo (zonas Norte e Central e partes das zonas Leste e Oeste) e Taboão da Serra. 


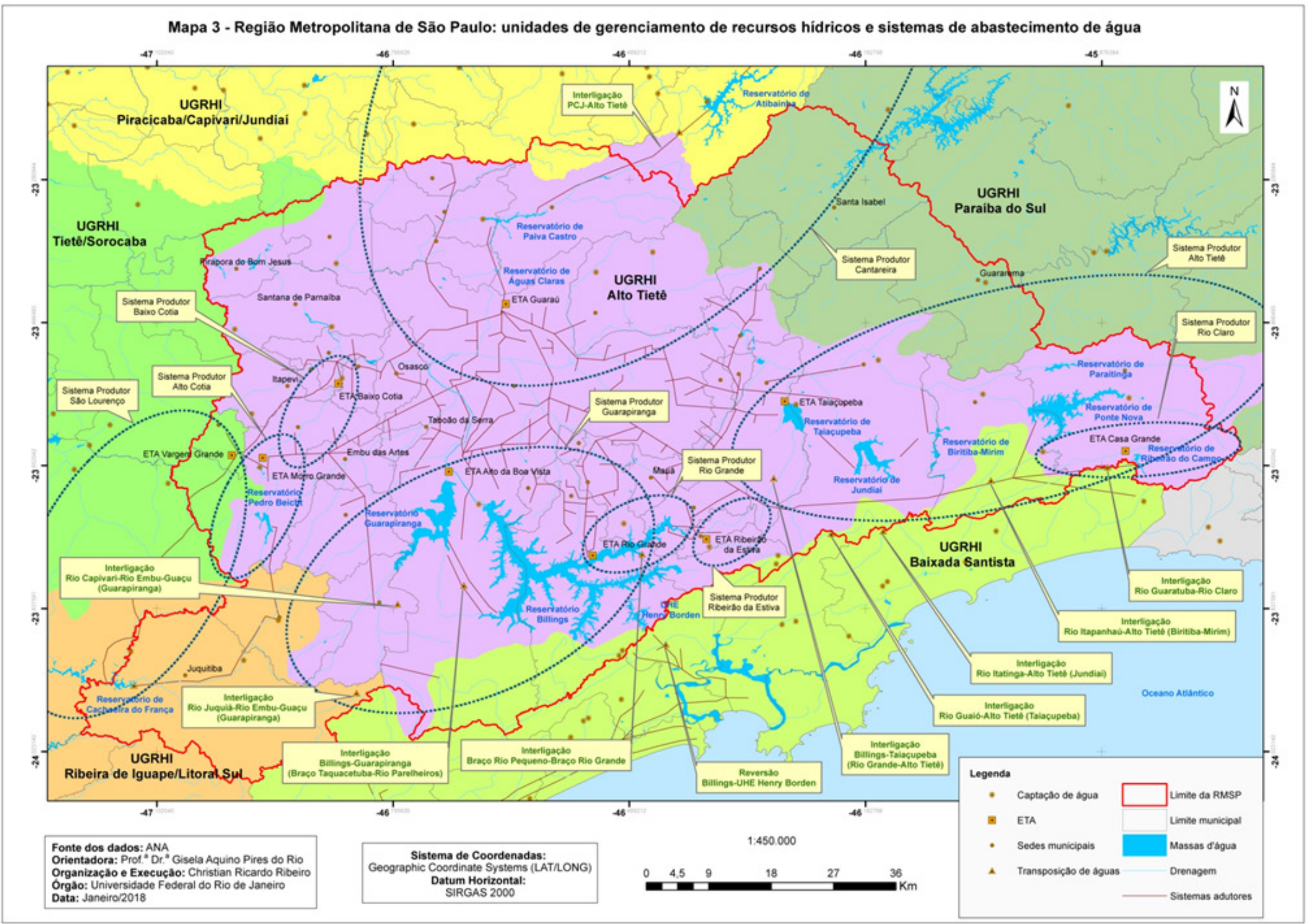




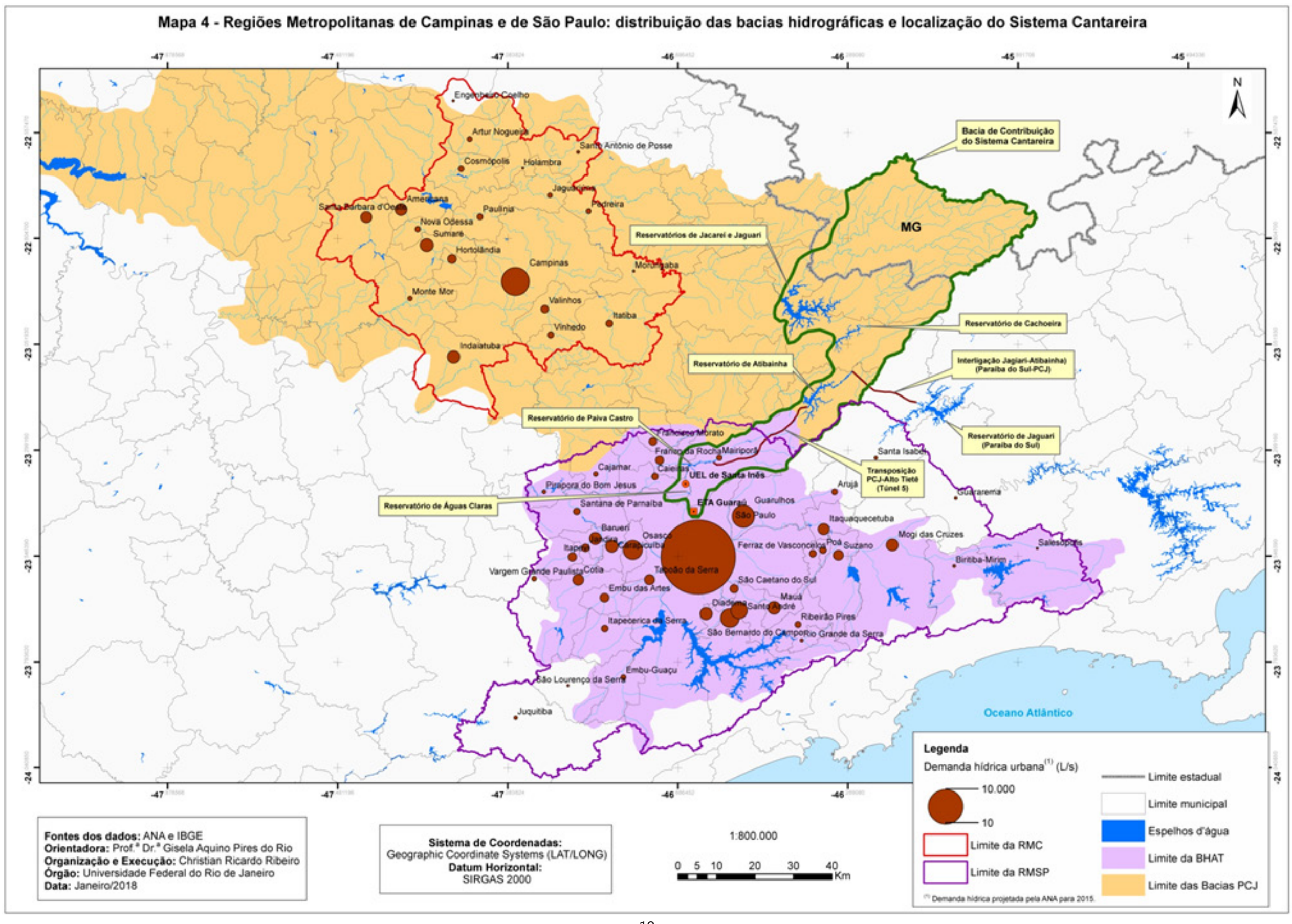


A superfície de regulação representada pelas redes técnicas de infraestrutura circunscreve as escalas nas quais atuam os atores responsáveis pela operação das redes de abastecimento de água e pela prestação dos serviços correspondentes na RMSP, atribuições que estão a cargo da Companhia de Saneamento Básico do Estado de São Paulo (SABESP). A companhia é a responsável atualmente pela prestação direta desses serviços para clientes residenciais, comerciais, públicos e industriais em 367 municípios do Estado de São Paulo e fornece água por atacado para cinco municípios da RMSP, o que representa cerca de $66 \%$ da população urbana estadual (27,7 milhões de pessoas). A gestão das águas da RMSP é, assim, fortemente condicionada pela atuação da SABESP.

Diferentemente da BHRPS, o Sistema Cantareira não dispõe de reservatórios destinados à geração de energia. Contudo, a RMSP é o espaço de atuação da Empresa Metropolitana de Águas e Energia (EMAE), uma sociedade de capital aberto controlada pelo Governo do Estado de São Paulo, constituída em 22 de dezembro de 1997 pela incorporação de parcelas do patrimônio cindido da Eletricidade de São Paulo S.A. (Eletropaulo). A EMAE é a detentora e a operadora do sistema hidráulico e gerador de energia (cinco usinas hidroelétricas e uma usina termoelétrica) localizado na RMSP, na Baixada Santista e no Médio Tietê, voltado ao aproveitamento múltiplo dos recursos hídricos para o atendimento de usos como a geração de energia hidroelétrica, o controle de cheias, o fornecimento de água bruta para o abastecimento público, o lazer e a pesca.

Da mesma forma que na RMRJ, existe uma forte interdependência entre a expansão, o adensamento e a integração dos sistemas de abastecimento de água e a

dinâmica do fenômeno metropolitano na RMSP. Por meio de sistemas de transposição, a RMSP passou a importar águas de bacias hidrográficas vizinhas à BHAT. Além do Sistema Cantareira, que permite o compartilhamento de águas entre as regiões metropolitanas de Campinas e de São Paulo (Mapa 4), existem as várias transposições de rios da vertente atlântica da Serra do Mar para o planalto paulista e, em sentido contrário, a reversão do Sistema PinheiroBillings para a Usina Hidroelétrica Henry Borden, que viabilizam o compartilhamento de águas entre as regiões metropolitanas da Baixada Santista e de São Paulo; o Sistema São Lourenço, que permite a transposição de águas da Bacia Hidrográfica do Ribeira de Iguape e Litoral Sul para a BHAT e o seu compartilhamento entre as regiões metropolitanas de Sorocaba e de São Paulo; e, por fim, a transposição de águas da BHRPS para as Bacias PCJ e, posteriormente, para a BHAT, por meio do Sistema Cantareira, permitindo o seu compartilhamento entre as regiões metropolitanas do Vale do Paraíba e Litoral Norte, de Campinas (RMC) e de São Paulo.

As unidades regionais que constituem a MMP estão sendo progressivamente conectadas e sincronicamente articuladas pelas redes técnicas de infraestrutura de abastecimento de água, conferindo-lhe uma maior coesão territorial (PIRES DO RIO, DRUMMOND e RIBEIRO, 2016). A associação entre o Mapa 3 , que apresenta a distribuição espacial dos sistemas de abastecimento de água nas unidades hidrográficas da RMSP, e o Mapa 4, que apresenta as demandas hídricas dos municípios da RMC e da RMSP - refletindo, por sua vez, a respectiva distribuição espacial da população e das áreas urbanizadas - evidencia a posição estratégica ocupada pela metrópole paulistana, localizada na interseção entre várias UGRHIs e compartilhando os recursos hídricos das Bacias PCJ com a RMC por meio do Sistema Cantareira. O conjunto formado pela RMC e pela RMSP concentrará a maior parte da demanda hídrica projetada para a MMP até $\mathrm{o}$ ano de 2035, tanto em termos de demanda total, quanto de demanda setorial (Tabela 2).

\begin{tabular}{|c|c|c|c|c|c|c|c|c|c|}
\hline \multirow[t]{2}{*}{ UGRHIs } & \multicolumn{3}{|c|}{ Tendencial } & \multicolumn{3}{|c|}{$\begin{array}{l}\text { Intensificação do } \\
\text { Crescimento }\end{array}$} & \multicolumn{3}{|c|}{$\begin{array}{c}\text { Ações e Controle } \\
\text { Operacional }\end{array}$} \\
\hline & URB & IRR & IND & URB & IRR & IND & URB & IRR & IND \\
\hline Paraiba do Sul & 7,85 & 6,64 & 6,96 & 8,45 & 6,64 & 7,75 & 6,49 & 5,81 & 6,67 \\
\hline Litoral Norte & 1,34 & 0,10 & 0,59 & 1,58 & 0,10 & 0,70 & 0,95 & 0,10 & 0,55 \\
\hline Piracicaba/Capivari/Jundiai (1) & 22,37 & 19,23 & 17,13 & 24,98 & 19,23 & 18,88 & 18,79 & 17,30 & 16,33 \\
\hline Alto Tietê $\hat{e}^{\left.(1)^{2}\right)}$ & 82,84 & 4,54 & 39,56 & 86,72 & 4,54 & 40,31 & 72,40 & 3,96 & 37,70 \\
\hline Baixada Santista(1) & 9,29 & 0,02 & 10,12 & 10,97 & 0,02 & 12,10 & 6,69 & 0,02 & 9,61 \\
\hline Mogi Guaçu & 2,44 & 10,76 & 4,91 & 1,98 & 10,76 & 4,21 & 2,02 & 9,68 & 4,68 \\
\hline Tietê/Sorocaba ${ }^{(1)}$ & 8,10 & 20,48 & 7,59 & 8,46 & 20,48 & 7,39 & $\frac{2,39}{6,39}$ & 17,81 & 7,24 \\
\hline Ribeira de Iguape/Litoral Sul & 0,18 & 0,00 & 0,00 & 0,15 & 0,00 & 0,00 & 0,16 & 0,00 & 0,00 \\
\hline Total por Uso & 134,41 & 61,80 & 86,86 & 143,31 & 61,80 & 91,36 & 113,93 & 54,71 & 82,80 \\
\hline Demanda Total & & 283,07 & & & 296,47 & & & 251,44 & \\
\hline
\end{tabular}

Fonte: GESP/SSRH/DAEE (2013, p. 09). Legenda: URB = urbano; IRR = irrigação; IND = industrial.

Notas: (1) UGRHIs totalmente inseridas na MMP. (2) A demanda industrial do Município de São Paulo, pertencente à UGRHI 06 (Alto Tietê), inclui as outorgas da Empresa Metropolitana de Aguas e Energia S.A. (EMAE), cadastradas como finalidade industrial, que somam $27,8 \mathrm{~m}^{3} / \mathrm{s}$ para a geração de energia elétrica na Usina Termoelétrica de Piratininga. 
A UGRHI Alto Tietê encontra-se, segundo Carmo (2001), em uma situação-limite, resultante da combinação de fatores como a manutenção da expansão da concentração populacional, principalmente nas áreas periféricas; a existência de um pólo industrial significativo; a superexploração dos mananciais; e a imposição de rodízio no abastecimento de água em algumas áreas. A demanda hídrica somente pode ser suprida com a importação de água de regiões vizinhas, principalmente a UGRHI PCJ, que também passa por um processo de aumento da demanda, contribuindo para intensificar a competição regional pelo uso dos recursos hídricos. A demanda hídrica na UGRHI Alto Tietê já corresponde a mais que o dobro da disponibilidade hídrica, ao passo que na UGRHI PCJ a relação entre demanda e disponibilidade é de 90\% (EMPLASA, 2015).

A mais recente expansão do sistema de abastecimento de água da RMSP, em termos de incorporação de novos mananciais, refere-se ao aproveitamento do Rio Juquiá, viabilizado por meio da construção do Sistema Produtor São Lourenço. A reversão das águas do Alto Juquiá, um manancial localizado na UGRHI Ribeira de Iguape/Litoral Sul, fora dos limites da RMSP, era uma alternativa considerada em todos os planos regionais de recursos hídricos elaborados desde a década de 1960, com diferentes concepções técnicas. O sistema garante a derivação de uma vazão de $4,7 \mathrm{~m} 3 / \mathrm{s}$ para o abastecimento público na RMSP, complementando a vazão disponibilizada pelos sistemas Alto Cotia, Baixo Cotia, Cantareira e Guarapiranga, integrando-se ao sistema de produção e de adução de água já existente e em operação na RMSP.

O PDARH-MMP apresentou a estimativa da demanda hídrica para $2008(222,96 \mathrm{m3} / \mathrm{s})$ e elaborou três cenários de crescimento da demanda hídrica, incluindo um tendencial $(283,07 \mathrm{~m} 3 / \mathrm{s})$. Baseando-se na premissa de que a demanda a ser atendida seria aquela prevista no cenário tendencial, o plano indicou cinco UGRHIs, incluindo a UGRHI 2 (Paraíba do Sul), como as alternativas para o aumento da disponibilidade hídrica e a garantia do abastecimento de água da MMP até 2035. A fase inicial do plano levantou um total de 27 esquemas, divididos em próprios e variantes, analisados segundo parâmetros técnicos, ambientais e institucionais (COBRAPE, 2013).

Entre os arranjos que previam a captação de água na UGRHI 2, estava a operação de interligação entre os reservatórios de Jaguari e de Atibainha (Arranjo 5), com vazões médias de captação variando entre 1,45 e $5,13 \mathrm{~m} 3 / \mathrm{s}$ e vazões máximas entre 2,0 e $8,5 \mathrm{~m} 3 / \mathrm{s}$. 0
PDARH-MMP propôs uma hierarquização dos arranjos identificados em três níveis de implantação, tendo o Arranjo 5 sido enquadrado no nível 3 , representado pelas soluções que envolviam a implementação de grandes obras e a resolução de questões político-institucionais, territoriais e de engenharia mais complexas, passíveis de entrar em operação a partir de 2030. Contudo, o agravamento da crise de abastecimento de água motivou o governo paulista a manifestar publicamente, em 19 de março de 2014, a intenção de executar a interligação. Argumentava-se que a proposta não era uma resposta imediatista à crise no Sistema Cantareira, que o projeto teria sido apresentado aos governadores dos demais estados envolvidos (Minas Gerais e Rio de Janeiro) e que a retirada de água adicional do Rio Paraíba do Sul por São Paulo não iria prejudicar o abastecimento do Estado do Rio de Janeiro em termos de quantidade e de qualidade.

Na Região Metropolitana de Campinas, por sua vez, a principal obra refere-se ao Sistema Produtor Regional $P C J$, que inclui os reservatórios de Pedreira (Rio Jaguari) e de Duas Pontes (Rio Camanducaia), com vazões regularizadas de $8,5 \mathrm{~m} 3 / \mathrm{s}$ e de $8,7 \mathrm{~m} 3 / \mathrm{s}$, respectivamente. O sistema produtor deverá ser complementado com a implantação do Sistema Adutor Metropolitano de Campinas, um conjunto de adutoras e de subadutoras, de reservatórios e de estações elevatórias que abrangerão a maior parte da área da região metropolitana e interligarão os seus principais sistemas produtores de água.

As superfícies de regulação e os atores da gestão das águas

A dependência da RMRJ em relação ao Rio Paraíba do Sul, projetando o seu abastecimento na escala regional, foi evidenciada pela crise de abastecimento de água. Nessa escala se evidenciam e se articulam os atores intervenientes na gestão das águas, cujas estratégias e práticas não estão circunscritas, em grande medida, aos limites político-administrativos dos municípios que compõem a RMRJ e do próprio Estado do Rio de Janeiro, bem como aos limites naturais das Regiões Hidrográficas (Baía de Guanabara e Guandu) a eles superpostas. 0 Quadro 1 apresenta os órgãos e as entidades representativos da densidade institucional interveniente no processo de gestão das águas que abastecem a RMRJ, vinculados às diferentes superfícies de regulação. 


\begin{tabular}{|c|c|c|c|}
\hline \multicolumn{4}{|c|}{$\begin{array}{c}\text { Quadro } 1 \text { - Superfícies de regulação e densidade institucional intervenientes na gestão das águas que abastecem a } \\
\text { Regiäo Metropolitana do Rio de Janeiro (2014-2015) }\end{array}$} \\
\hline $\begin{array}{c}\text { Superficie de } \\
\text { regulacão }\end{array}$ & Espaço de atuação & $\begin{array}{l}\text { Nível territorial/ } \\
\text { Domínio hídrico }\end{array}$ & Orgãos e entidades \\
\hline \multirow{3}{*}{$\begin{array}{l}\text { Malha Político- } \\
\text { Administrativa }\end{array}$} & $\begin{array}{l}\text { Estado do Rio de } \\
\text { Janeiro }\end{array}$ & Estadual & $\begin{array}{l}\text { Secretarias de Estado com interveniência direta e/ou indireta na } \\
\text { gestäo das águas e os respectivos órgãos e entidades a elas } \\
\text { vinculados: Secretaria de Estado da Casa Civil e Desenvolvimento } \\
\text { Econômico (CASA CIVIL), Secretaria de Estado de Obras } \\
\text { (SEOBRAS) e Secretaria de Estado do Ambiente (SEA) }\end{array}$ \\
\hline & $\begin{array}{l}\text { Região Metropolitana } \\
\text { do Rio de Janeiro }\end{array}$ & Metropolitano & $\begin{array}{l}\text { Secretarias de Estado com interveniência direta e/ou indireta na } \\
\text { gestäo das águas e os respectivos órgãos e entidades a elas } \\
\text { vinculados - Secretaria de Estado de Governo (SEGOV) e } \\
\text { Secretaria de Estado de Obras (SEOBRAS) - e Prefeituras } \\
\text { Municipais (consórcios intermunicipais) }\end{array}$ \\
\hline & $\begin{array}{c}\text { Municipios } \\
\text { metropolitanos (21) }\end{array}$ & Municipal & $\begin{array}{l}\text { Secretarias, conselhos, autarquias e fundações mumicipais com } \\
\text { interveniência direta e/ou indireta na gestão das águas }\end{array}$ \\
\hline \multirow{3}{*}{$\begin{array}{c}\text { Bacia } \\
\text { Hidrográfica }\end{array}$} & $\begin{array}{l}\text { Bacia Hidrográfica do } \\
\text { Rio Paraíba do Sul }\end{array}$ & Federal & $\begin{array}{l}\text { Sistema Nacional de Gerenciamento de Recursos Hidricos } \\
\text { (SINGREH): Conselho Nacional de Recursos Hidricos (CNRH), } \\
\text { Agência Nacional de Aguas (ANA), Comitê de Integração da } \\
\text { Bacia Hidrográfica do Rio Paraiba do Sul (CEIVAP) e Agência } \\
\text { Pró-Gestão das Aguas da Bacia Hidrográfica do Rio Paraiba do Sul } \\
\text { (AGEVAP) }\end{array}$ \\
\hline & $\begin{array}{l}\text { Regiôes Hidrográficas } \\
\text { Guandu (RH-II), } \\
\text { Médio Paraiba do Sul } \\
\text { (RH-III) e Baia de } \\
\text { Guanabara (RH-V) }\end{array}$ & Estadual & $\begin{array}{l}\text { Sistema Estadual de Gerenciamento de Recursos Hidricos } \\
\text { (SEGRHI-RJ): Conselho Estadual de Recursos Hidricos do Rio de } \\
\text { Janeiro (CERHI-R), Instituto Estadual do Ambiente (INEA), } \\
\text { Fundo Estadual de Recursos Hidricos do Rio de Janeiro } \\
\text { (FUNDRHI-R), Comitê das Bacias Hidrográficas dos Rios } \\
\text { Guandu, da Guarda e Guandu-Mirim (CBH-Guandu), Comitê da } \\
\text { Bacia da Regiâo Hidrográfica do Médio Paraiba do Sul (CBH- } \\
\text { MPS), Comitê da Região Hidrografica da Baia de Guanabara e dos } \\
\text { Sistemas Lagunares de Maricá e Jacarepaguá (CBH-BG) e } \\
\text { Agência Pró-Gestão das Ásguas da Bacia Hidrográfica do Rio } \\
\text { Paraíba do Sul (AGEVAP) }\end{array}$ \\
\hline & $\begin{array}{l}\text { Unidade de } \\
\text { Gerenciamento de } \\
\text { Recursos Hidricos } \\
\text { Paraiba do Sul } \\
\text { (UGRHI 2) }\end{array}$ & Estadual & $\begin{array}{l}\text { Sistema Integrado de Gerenciamento de Recursos Hidricos do } \\
\text { Estado de São Paulo (SIGRH-SP): Conselho Estadual de Recursos } \\
\text { Hidricos de São Paulo (CRH-SP), Departamento de Aguas e } \\
\text { Energia Elétrica (DAEE), Fundo Estadual de Recursos Hidricos de } \\
\text { São Paulo (FEHIDRO-SP) e Comitê das Bacias Hidrográficas do } \\
\text { Rio Paraíba do Sul (CBH-PS) }\end{array}$ \\
\hline \multirow{7}{*}{$\begin{array}{l}\text { Rede Técnica de } \\
\text { Infraestrutura }\end{array}$} & \multirow{2}{*}{$\begin{array}{l}\text { Area de influência do } \\
\text { Sistema } \\
\text { Imunana-Laranjal }\end{array}$} & Municipal & $\begin{array}{l}\text { Concessionárias do Setor de Abastecimento e Saneamento: Aguas } \\
\text { de Niterói (Grupo Águas do Brasil) }\end{array}$ \\
\hline & & Metropolitano & $\begin{array}{l}\text { Concessionárias do Setor de Abastecimento e Saneamento: } \\
\text { Companhia Estadual de Ásuas e Esgotos (CEDAE) }\end{array}$ \\
\hline & \multirow{2}{*}{$\begin{array}{l}\text { Area de influência do } \\
\text { Sistema Integrado } \\
\text { Acari-Guandu-Lajes } \\
\text { (transposição Paraíba } \\
\text { do Sul-Guandu) }\end{array}$} & Municipal & $\begin{array}{l}\text { Concessionárias do Setor de Abastecimento e Saneamento: FAB } \\
\text { Zona Oeste S.A. (Rio de Janeiro), Central de Águas e Saneamento } \\
\text { de Duque de Caxias (CASDUC) e Fontes da Serra Saneamento de } \\
\text { Guapimirim }\end{array}$ \\
\hline & & $\begin{array}{l}\text { Metropolitano- } \\
\text { Regional }\end{array}$ & $\begin{array}{l}\text { Concessionárias do Setor de Abastecimento e Saneamento: } \\
\text { Companhia Estadual de Águas e Esgotos (CEDAE) }\end{array}$ \\
\hline & $\begin{array}{l}\text { Area de influência dos } \\
\text { sigtemas isolados }\end{array}$ & nicipal & $\begin{array}{l}\text { Concessionárias do Setor de Abastecimento e Saneamento: } \\
\text { Companhia Estadual de Ásuas e Esgotos (CEDAE) }\end{array}$ \\
\hline & \multirow{2}{*}{$\begin{array}{l}\text { Area de influência dos } \\
\text { Complexos } \\
\text { Hidroelétricos de } \\
\text { Paraiba do Sul-Lajes e } \\
\text { de Ribeirão das Lajes } \\
\text { (ETA Guandu e Calha } \\
\text { da CEDAE) }\end{array}$} & \multirow{2}{*}{ Regional } & $\begin{array}{l}\text { Concessionárias do Setor de Geração de Energia Elétrica: Light } \\
\text { Energia (Grupo Light), Companhia Energética de São Paulo } \\
\text { (CESP) e Eletrobras Furnas }\end{array}$ \\
\hline & & & $\begin{array}{l}\text { Coordenação e Controle da Operação do Setor de Energia Elétrica: } \\
\text { Operador Nacional do Setor Elétrico (ONS) }\end{array}$ \\
\hline
\end{tabular}

Fonte: sítios eletrônicos dos governos estaduais, das prefeituras municipais, dos órgãos colegiados de gestão de recursos hídricos e das concessionárias dos setores de geração de energia elétrica e de serviços de saneamento básico. Elaborado pelo autor.

A malha político-administrativa circunscreve a atuação de órgãos e de entidades vinculados a três esferas de decisão: o Estado do Rio de Janeiro, a Região Metropolitana do Rio de Janeiro e os 21 municípios metropolitanos. A bacia hidrográfica (Regiões Hidrográficas) constitui uma superfície de regulação cujo marco legal de referência é a Lei Estadual n.o 3.239, de 02 de agosto de 1999, que institui a Política Estadual de Recursos Hídricos (PERH-RJ) e cria o Sistema Estadual de Gerenciamento de Recursos Hídricos do Rio de Janeiro (SEGRHI-RJ). O SEGRHI-RJ é composto, além de órgãos e de entidades de gestão de recursos hídricos diretamente vinculados ao Poder Executivo estadual, pelos Comitês de Bacia Hidrográfica, pelas Agências de Água e pelos demais organismos dos poderes públicos federal, estadual e municipais correlacionados.

Finalmente, a rede técnica de infraestrutura circunscreve as escalas nas quais atuam os atores responsáveis pela operação dos serviços de abastecimento de água na RMRJ. A gestão da crise foi articulada predominantemente na escala regional, a partir da centralização das decisões não por parte dos 
atores vinculados à bacia hidrográfica, ao SEGRHI-RJ e ao SINGREH, mas pelos atores responsáveis pela operação dos sistemas e das redes de abastecimento de água da RMRJ, integrados às estruturas hidráulicas de produção de energia hidroelétrica. A principal medida de gestão da crise na área de influência do Sistema Hidráulico do Rio Paraíba do Sul (SHRPS), do qual depende a RMRJ para o seu abastecimento de água, refere-se às reduções da vazão-objetivo na Usina Elevatória de Santa Cecília, implementadas com base nas discussões realizadas no âmbito do Grupo de Trabalho Permanente de Acompanhamento da Operação Hidráulica na Bacia Hidrográfica do Rio Paraíba do Sul (GTAOH).

O GTAOH é um grupo de trabalho constituído no âmbito do CEIVAP, instituído originalmente por meio da Deliberação Normativa n.o 53, de 16 de setembro de 2005, com o objetivo de antecipar e de analisar os conflitos envolvendo a operação hidráulica dos reservatórios do Rio Paraíba do Sul e os usos múltiplos da água, incluindo a transposição para o Rio Guandu. 0 grupo conta com a participação de representantes do CEIVAP, do CBH-Guandu e dos sete comitês afluentes ao CEIVAP, dos órgãos gestores de recursos hídricos (DAEE, IGAM e INEA) e dos órgãos de controle ambiental dos três estados da BHRPS, dos municípios, dos usuários de recursos hídricos (saneamento, indústria e geração de energia), da ANA, da ANEEL e do ONS. O GTAOH teve uma forte atuação durante a crise de 2014-2015, tendo realizado um total de 19 reuniões em 2014 e de 30 reuniões em 2015, com uma frequência quinzenal ou semanal. As discussões realizadas no âmbito do grupo subsidiaram a elaboração da Resolução Conjunta ANADAEE-IGAM-INEA n.o 1.382, de 07 de dezembro de 2015, que substituiu definitivamente a Resolução ANA n.o 211, de 26 de maio de 2003, que dispõe sobre as regras de operação do Sistema Hidráulico do Rio Paraíba do Sul.

A gestão da crise, realizada basicamente por meio da implementação de medidas de controle de vazões autorizadas pela ANA a partir das discussões realizadas no âmbito do GTAOH, fortemente condicionadas pela atuação dos órgãos gestores de recursos hídricos (estaduais e federal) e pelas demandas setoriais das companhias de geração de energia elétrica e de abastecimento de água, reforça a falta de protagonismo dos órgãos colegiados de gestão de recursos hídricos. De uma maneira geral, a fraca capacidade de implementação de decisões, sobretudo em situações emergenciais, continua sendo uma lacuna importante para a maior parte dos órgãos deliberativos atuantes na gestão dos recursos hídricos no Brasil. No caso do CEIVAP, por exemplo, a sua atuação durante a crise se concentrou na liberação de recursos financeiros oriundos da cobrança pelo uso de recursos hídricos para a realização de intervenções estruturais nas captações de água dos municípios fluminenses e paulistas no Rio Paraíba do Sul.

No caso da RMSP, a crise também evidenciou que o abastecimento de água se projeta na escala regional, haja vista a sua forte dependência em relação ao Sistema Cantareira, cuja região produtora de água (Bacias PCJ) sofreu de uma maneira mais intensa e prolongada com a estiagem. Os atores intervenientes na gestão das águas que abastecem a RMSP não têm a sua atuação circunscrita aos limites político-administrativos dos municípios que a constituem e do Estado de São Paulo, nem aos limites naturais da UGRHI Alto Tietê, na qual se localiza a maior parte de sua área de abrangência. 0 Quadro 2 apresenta os órgãos e as entidades vinculadas às diferentes superfícies de regulação intervenientes na gestão das águas que abastecem a RMSP.

A malha político-administrativa circunscreve a atuação de órgãos e de entidades vinculados a três níveis, instâncias ou esferas de decisão: o Estado de São Paulo, a Região Metropolitana de São Paulo e os 39 municípios metropolitanos. A bacia hidrográfica (Unidades de Gerenciamento de Recursos Hídricos) constitui uma superfície de regulação cujo marco legal de referência é a Lei Estadual n.o 7.663, de 30 de dezembro de 1991, que instituiu o Sistema Integrado de Gerenciamento de Recursos Hídricos de São Paulo (SIGRH-SP). O sistema é o responsável por executar a Política Estadual de Recursos Hídricos de São Paulo, sendo integrado por um conjunto de órgãos e de entidades com competências de ordem deliberativa, técnica e/ou financeira. 


\begin{tabular}{|c|c|c|c|}
\hline \multicolumn{4}{|c|}{$\begin{array}{c}\text { Quadro } 2 \text { - Superficies de regulação e densidade institucional intervenientes na gestão das águas que abastecem a } \\
\text { Região Metropolitana de São Paulo (2014-2015) }\end{array}$} \\
\hline $\begin{array}{l}\text { Superficie de } \\
\text { regulação }\end{array}$ & Espaço de atuação & $\begin{array}{l}\text { Nível territorial } \\
\text { Domínio hidrico }\end{array}$ & Órgãos e entidades \\
\hline \multirow{4}{*}{$\begin{array}{l}\text { Malha Político- } \\
\text { Administrativa }\end{array}$} & Estado de São Paulo & Estadual & $\begin{array}{l}\text { Secretarias de Estado com interveniência direta e/ou indireta } \\
\text { na gestão das águas e os respectivos órgãos e entidades a elas } \\
\text { vinculados: Secretaria de Estado de Saneamento e Recursos } \\
\text { Hidricos (SSRH), Secretaria de Estado do Meio Ambiente } \\
\text { (SMA) e Secretaria de Estado de Energia e Mineração (SEM) }\end{array}$ \\
\hline & Macrometrópole Paulista & Macrometropolitano & Não institucionalizada \\
\hline & $\begin{array}{l}\text { Regiào Metropolitana de } \\
\text { São Paulo }\end{array}$ & Metropolitano & $\begin{array}{l}\text { Secretarias de Estado com interveniência direta e/ou indireta } \\
\text { na gestão das águas e os respectivos órgãos e entidades a elas } \\
\text { vinculados - Secretaria de Estado da Casa Civil (CASA } \\
\text { CIVIL)/Subsecretaria de Assuntos Metropolitanos (SDM) -e } \\
\text { Prefeituras Municipais (consórcios intermunicipais) }\end{array}$ \\
\hline & $\begin{array}{l}\text { Municipios metropolitanos } \\
\text { (39) }\end{array}$ & Municipal & $\begin{array}{l}\text { Secretarias (ou órgãos equivalentes), conselhos, autarquias e } \\
\text { fundaçôes municipais com interveniência direta e/ou indireta } \\
\text { na gestão das águas }\end{array}$ \\
\hline \multirow{3}{*}{$\begin{array}{l}\text { Bacia } \\
\text { Hidrográfica }\end{array}$} & $\begin{array}{c}\text { Bacias Hidrográficas dos } \\
\text { Rios Piracicaba, Capivari e } \\
\text { Jundiai }\end{array}$ & Federal & $\begin{array}{l}\text { Sistema Nacional de Gerenciamento de Recursos Hidricos } \\
\text { (SNNGREH): Conselho Nacional de Recursos Hidricos } \\
\text { (CNRH), Agência Nacional de Aguas (ANA), Comitê das } \\
\text { Bacias Hidrograficas dos Rios Piracicaba, Capivari e Jundiai } \\
\text { (PCJ FEDERAL), Agência de Agua das Bacias Hidrográficas } \\
\text { dos Rios Piracicaba, Capivari e Jundiai (Agência PCJ) e } \\
\text { Consórcio Intermunicipal das Bacias dos Rios Piracicaba, } \\
\text { Capivari e Jundiai (Consórcio PCJ) }\end{array}$ \\
\hline & $\begin{array}{l}\text { Unidades de } \\
\text { Gerenciamento de } \\
\text { Recursos Hidricos } \\
\text { Piracicaba/Capivari/Jundiai } \\
\text { (5), Alto Tietê (6) e Ribeira } \\
\text { de Iguape/Litoral Sul (11) }\end{array}$ & Estadual & $\begin{array}{l}\text { Sistema Integrado de Gerenciamento de Recursos Hidricos } \\
\text { do Estado de São Paulo (SIGRH-SP): Conselho Estadual de } \\
\text { Recursos Hidricos de São Paulo (CRH-SP), Departamento de } \\
\text { Aguas e Energia Elétrica (DAEE), Comitê Coordenador do } \\
\text { Plano Estadual de Recursos Hidricos (CORHI-SP), Fundo } \\
\text { Estadual de Recursos Hidricos de São Paulo (FEHIDRO-SP), } \\
\text { Comitê das Bacias Hidrográicas dos Rios Piracicaba, } \\
\text { Capivari e Jundiai (CBH-PCJ), Comitê da Bacia Hidrográfica } \\
\text { do Alto Tietê (CBH-AT), Comitê da Bacia Hidrográfica do } \\
\text { Ribeira de Iguape e Litoral Sul (CBH-RILS), Agência da } \\
\text { Bacia Hidrográfica do Alto Tietê (FABHAT), Agência de } \\
\text { Agua das Bacias Hidrográficas dos Rios Piracicaba e } \\
\text { Capivari e Jundiai (Agência PCJ) }\end{array}$ \\
\hline & $\begin{array}{l}\text { Unidade de Planejamento e } \\
\text { Gestão de Recursos } \\
\text { Hidricos dos Rios } \\
\text { Piracicaba e Jaguari (PJ1) }\end{array}$ & Estadual & $\begin{array}{l}\text { Sistema Estadual de Gerenciamento de Recursos Hidricos de } \\
\text { Minas Gerais (SEGRH-MG): Conselho Estadual de Recursos } \\
\text { Hidricos (CERH-MG), Instituto Mineiro de Gestão das } \\
\text { Aguas (IGAM), Fundo de Recuperação, Proteção e } \\
\text { Desenvolvimento Sustentável das Bacias Hidrográficas do } \\
\text { Estado de Minas Gerais (FHIDRO) e Comitê da Bacia } \\
\text { Hidrográfica dos Rios Piracicaba e Jaguari (CBH-PJ) }\end{array}$ \\
\hline \multirow{6}{*}{$\begin{array}{l}\text { Rede Técnica de } \\
\text { Infraestrutura }\end{array}$} & \multirow{3}{*}{$\begin{array}{l}\text { Area de influência dos } \\
\text { gistemas Alto Cotia, Baixo } \\
\text { Cotia, Alto Tietê, } \\
\text { Guarapiranga, Ribeirão da } \\
\text { Estiva, Rio Claro e Rio } \\
\text { Grande }\end{array}$} & Municipal & $\begin{array}{l}\text { Concessionárias do Setor de Abastecimento e Saneamento: } \\
\text { Companhia de Saneamento de Diadema, Serviço Autônomo } \\
\text { de Agua e Esgoto de Guarulhos, Serviço Municipal de } \\
\text { Saneamento Ambiental de Santo André, Serviço Municipal } \\
\text { de Aguas e Esgotos de Mogi das Cruzes e Saneamento } \\
\text { Básico do Municipio de Mauá }\end{array}$ \\
\hline & & \multirow[b]{2}{*}{ Metropolitano } & $\begin{array}{l}\text { Concessionárias do Setor de Abastecimento e Saneamento: } \\
\text { Companhia de Saneamento Básico do Estado de São Paulo } \\
\text { (SABESP) }\end{array}$ \\
\hline & & & $\begin{array}{l}\text { Concessionárias do Setor de Geração de Energia Elétrica } \\
\text { (reversão Tietê/Pinheirog-Reservatório Billings-UHE Henry } \\
\text { Borden): Empresa Metropolitana de Aguas e Energia } \\
\text { (EMAE) }\end{array}$ \\
\hline & \multirow{2}{*}{$\begin{array}{l}\text { Area de influência dos } \\
\text { sistemas Cantareira } \\
\text { (transposição PCJ-Alto } \\
\text { Tietê) e São Lourenço } \\
\text { (reversão Alto Juquià-Alto } \\
\text { Tietê) }\end{array}$} & Municipal & $\begin{array}{l}\text { Concessionárias do Setor de Abastecimento e Saneamento: } \\
\text { Serviço Autônomo de Água e Esgoto de Guarulhos e Sistema } \\
\text { de Agua, Esgoto e Saneamento Ambiental de São Caetano do } \\
\text { Sul }\end{array}$ \\
\hline & & $\begin{array}{l}\text { Metropolitano- } \\
\text { Regional }\end{array}$ & $\begin{array}{l}\text { Concessionárias do Setor de Abastecimento e Saneamento: } \\
\text { Companhia de Sameamento Básico do Estado de São Paulo } \\
\text { (SABESP) }\end{array}$ \\
\hline & $\begin{array}{l}\text { Area de influência dos } \\
\text { sistemas isolados }\end{array}$ & Municipal & $\begin{array}{l}\text { Concessionárias do Setor de Abastecimento e Saneamento: } \\
\text { Companhia de Sameamento Básico do Estado de São Paulo } \\
\text { (SABESP), Serviço Autônomo de Agua e Esgoto de } \\
\text { Guarulhos, Serviço Municipal de Saneamento Ambiental de } \\
\text { Santo André, Sistema de Agua, Esgoto e Sameamento } \\
\text { Ambiental de Sáo Caetano do Sul e Serviço Municipal de } \\
\text { Asuase-Esgotos deMogi das Cruzas }\end{array}$ \\
\hline
\end{tabular}

Fontes de pesquisa: sítios eletronicos dos governos estaduais, das prefeituras municipais, dos órgãos colegiados de gestão de recursos hídricos e das concessionárias dos setores de geração de energia elétrica e de serviços de saneamento básico. Organização: autor. 
A rede técnica de infraestrutura circunscreve as escalas nas quais atuam os atores responsáveis pela operação dos serviços de abastecimento de água na RMSP. Esses serviços são ofertados por meio do Sistema Integrado de Abastecimento de Água da RMSP, composto por nove subsistemas, descrito anteriormente neste trabalho. Também no caso da RMSP a gestão da crise foi articulada basicamente na escala regional, com uma forte centralização das medidas por parte da SABESP. O Cantareira foi o sistema de abastecimento de água da RMSP atingido de uma forma mais intensa pela situação de escassez hídrica e, por essa razão, a gestão da crise concentrou-se na implementação de medidas para o enfrentamento de seus impactos na área de influência desse sistema.

A gravidade assumida pela crise na RMSP obrigou à implementação de um conjunto de medidas mais amplo e diversificado em relação aquelas implementadas na área de influência do SHRPS. Uma dessas medidas foi a instituição do Grupo Técnico de Assessoramento à Gestão do Sistema Cantareira (GTAG-Cantareira). 0 grupo foi criado por meio da Resolução Conjunta ANADAEE n.o 120, de 10 de fevereiro de 2014, composto por representantes da ANA, do DAEE, do CBH-PCJ, do CBH-AT e da SABESP. O GTAG-Cantareira tinha como competências $O$ assessoramento das autoridades outorgantes nas decisões referentes à gestão do Sistema Cantareira e a recomendação de implementação de eventuais medidas de restrição ou de suspensão de usos da água aos usuários localizados na RMSP e nas Bacias PCJ. Contudo, após sete meses de funcionamento do grupo, a ANA se retirou do mesmo devido a discordâncias com a Secretaria de Estado de Saneamento e Recursos Hídricos de São Paulo (SSRH) a respeito da proposta de limites de retirada de água do Sistema Cantareira para a RMSP.

Várias outras medidas foram implementadas na área de influência do Sistema Cantareira. A maior parte delas foi proposta e executada pela SABESP, assumindo um caráter eminentemente conjuntural, emergencial e setorial. Destaca-se também o papel desempenhado pelo órgão gestor de recursos hídricos estadual de São Paulo (DAEE) na implementação dessas medidas, reforçando a centralização da gestão da crise. Os CBHs atuantes na área de influência do Sistema Cantareira, o que inclui a RMSP, tiveram uma expressiva dificuldade até mesmo na liberação de recursos financeiros para a realização de intervenções emergenciais. As medidas emergenciais, tais como a imposição de restrições de usos e a suspensão da concessão de novas outorgas, foram implementadas basicamente a partir de decisões do governo estadual, sob a justificativa de que as demandas decorrentes de uma conjuntura de crise são incompatíveis com os ritos que devem ser observados pelos órgãos colegiados de gestão de recursos hídricos.

\section{A crise de abastecimento de água e a emergência da} hidromegarregião

A crise de abastecimento de água alcançou uma grande repercussão ao manifestar-se sobre as duas maiores aglomerações metropolitanas brasileiras: Rio de Janeiro e São Paulo. Caracterizadas pela "conexão regional no plano da infraestrutura de serviços", as grandes aglomerações urbanas, expressas na forma de regiões metropolitanas e de cidades-região, exercem um enorme peso relativo na demanda hídrica decorrente do atendimento das necessidades dos usos consuntivos, ainda que não disponham de uma voz efetiva no processo de gestão das águas (PIRES DO RIO et al., 2011). A expressão "cidade-região", proposta originalmente por Scott et al. (2001), designa a forma urbana característica do processo de metropolização contemporâneo, em que "a urbanização sem fronteiras aparentes une no espaço conurbado metrópoles que outrora eram facilmente delimitáveis, e diversas regiões se tornam espaços inteiramente urbanizados, dando origem a uma nova entidade socioespacial" (MAGALHÃES, 2008, p. 09).

0 conjunto territorial formado pela Região Metropolitana de São Paulo e pelas aglomerações metropolitanas a ela associadas parece indicar a constituição de uma cidade-região que, por sua vez, integra uma "megarregião" ainda em formação, que tem como centros principais as metrópoles do Rio de Janeiro e de São Paulo. A Megarregião Rio de Janeiro-São Paulo, segundo Lencioni (2015), engloba uma cidaderegião, que corresponde à Macrometrópole Paulista, no território do Estado de São Paulo; e um conjunto territorial formado pela Região Metropolitana do Rio de Janeiro e o seu entorno, que inclui cinco microrregiões (Baía da llha Grande, Barra do Piraí, Lagos, Serrana e Vale do Paraíba), no território do Estado do Rio de Janeiro.

A crise projetou-se em uma escala geográfica mais ampla justamente quando o governo paulista tornou pública a decisão unilateral de implementar um novo projeto de transposição, ou de "interligação", entre o Reservatório de Jaguari, localizado na BHRPS, e o Reservatório de Atibainha, na Bacia Hidrográfica do Rio Piracicaba(BHRPI), como objetivo de reforçar a segurança hídrica da RMSP em períodos de escassez, por meio do Sistema Cantareira. 0 projeto era enquadrado como uma alternativa de longo prazo de implementação nos estudos de planejamento de recursos hídricos realizados pelo Estado de São Paulo desde 2008, mas foi alçado à 
condição de prioridade com a emergência da crise em 2014 e seus desdobramentos em 2015. Constituiu-se em um ponto de disputa e de tensionamento com o Estado do Rio de Janeiro, dada a forte dependência deste último em relação ao Rio Paraíba do Sul para o abastecimento de água de três quartos de sua população, concentrados na RMRJ.

Aindaqueosdoisreservatóriossejam dedominialidade estadual, a possibilidade de emergência de um conflito federativo demandou a mediação da Agência Nacional de Águas (ANA), que buscou conciliar os interesses dos dois estados por meio de consenso técnico e político. Contudo, a iniciativa do Ministério Público Federal no Rio de Janeiro (MPF-RJ), que solicitou ao Poder Judiciário a determinação de suspensão de todas as ações administrativas necessárias à implementação do projeto (licenciamento, outorga e obras), justificada pelos possíveis impactos em diferentes regiões do estado fluminense, conduziu à judicialização da questão. 0 impasse foi superado com a assinatura de um acordo pelos governadores dos três estados drenados pela BHRPS - Minas Gerais, Rio de Janeiro e São Paulo -, sob a mediação do Supremo Tribunal Federal (STF).

Os esquemas de transposição conferem inteligibilidade à crise, na medida em que evidenciam as relações estabelecidas entre as áreas produtoras e doadoras (bacias) e as áreas receptoras e consumidoras de água (metrópoles). Se a transposição PCJ-Alto Tietê, realizada por meio do Sistema Cantareira, expressa as disputas estabelecidas entre as metrópoles de Campinas e de São Paulo desde a década de 1970 pelo controle das águas das Bacias PCJ, a transposição Paraíba do SulGuandu, realizada por meio do Sistema Hidráulico do Rio Paraíba do Sul, reflete as tensões emergentes entre as regiões inseridas no interior da BHRPS, e entre as regiões inseridas em seu interior e as regiões externas à bacia, mas dela dependentes em termos de abastecimento de água. A operação dos reservatórios de regularização e das usinas hidroelétricas a eles associadas, situados no alto curso da bacia, no Estado de São Paulo, condiciona a disponibilidade hídrica necessária ao atendimento das demandas de usos consuntivos e não consuntivos tanto em outras regiões da própria bacia, situadas no Estado do Rio de Janeiro - Médio Paraíba do Sul e Baixo Paraíba do Sul -, quanto das demandas pelas vazões transpostas que garantem o abastecimento de água da RMRJ, territorialmente associada à BHRG.

A transposição Paraíba do Sul-PCJっ-Alto Tietê apresenta-se como uma inovação importante, na medida em que foi implementada na interseção das respectivas áreas de influência dos sistemas de abastecimento de água das regiões metropolitanas do Rio de Janeiro e de São Paulo, articulando-os e tensionando-os entre si e com as demais superfícies de regulação intervenientes na gestão de suas águas, conforme mostra o Mapa 5. A problemática do abastecimento de água foi projetada na escala regional, pois a BHRPS assume a função de manancial de abastecimento de água dessas aglomerações e de elo principal de uma "macrorregião hídrica" (FORMIGA-JOHNSSON et al., 2015) que expressa a emergência de uma nova espacialidade, coincidente, em grande medida, com a Megarregião Rio de JaneiroSão Paulo, tal como definida por Lencioni (2015).

Conforme apontam Pires do Rio, Drummond e Ribeiro (2016, p. 109), "as transposições integram, no tempo, o que denominamos malha hídrica, isto é, o conjunto de infraestrutura e instalações para extração, transporte, armazenamento e distribuição de água: açudes, represas, canais, cisternas, redes de distribuição e carros-pipa". Os autores ressaltam que essas soluções de engenharia expressam articulações e estabelecem sincronicidade entre unidades espaciais antes isoladas e não interligadas, colocam em interação uma grande diversidade de agentes e atores e constituem superfícies nas quais tensões, conflitos e disputas situados em torno de projetos unilaterais serão necessariamente regionais. Assim, se a malha hídrica da RMRJ cresceu em direção aos recursos hídricos disponíveis na BHRPS e os sistemas de abastecimento de água da RMSP, impulsionados pela urgência de enfrentamento da crise, passaram a expandir-se na mesma direção, a implementação da interligação entre os reservatórios de Atibainha e de Jaguari levou a termo o processo de construção da escala regional de gestão das águas, que delimita e circunscreve a emergência de uma nova espacialidade.

A constituição da megarregião hídrica é consequente à estratégia de "salto escalar" adotada pelo governo estadual paulista ao reconhecer a macrometrópole como uma nova unidade territorial de referência para o planejamento e a gestão de recursos hídricos, ampliando as suas alternativas de fontes de abastecimento de água (PIRES DO RIO, 2017). O conceito de jumping of scales, proposto por Smith (2004), refere-se à força de um determinado agente para transcender a escala original de abrangência de sua atuação. No caso específico, esse salto pôde ser operacionalizado porque as redes técnicas de infraestrutura de abastecimento de água estão progressivamente se adensando, se expandindo e se integrando, e conferindo, consequentemente, uma crescente "coesão territorial", entendida como uma criação dependente de um ambiente e de uma densidade institucionais específicos de uma região (PIRES DO RIO, 2009), entre as diferentes superfícies de regulação que, articuladas e sobrepostas, definem a extensão espacial da Hidromegarregião Rio de Janeiro-São Paulo (HMRRJSP). 


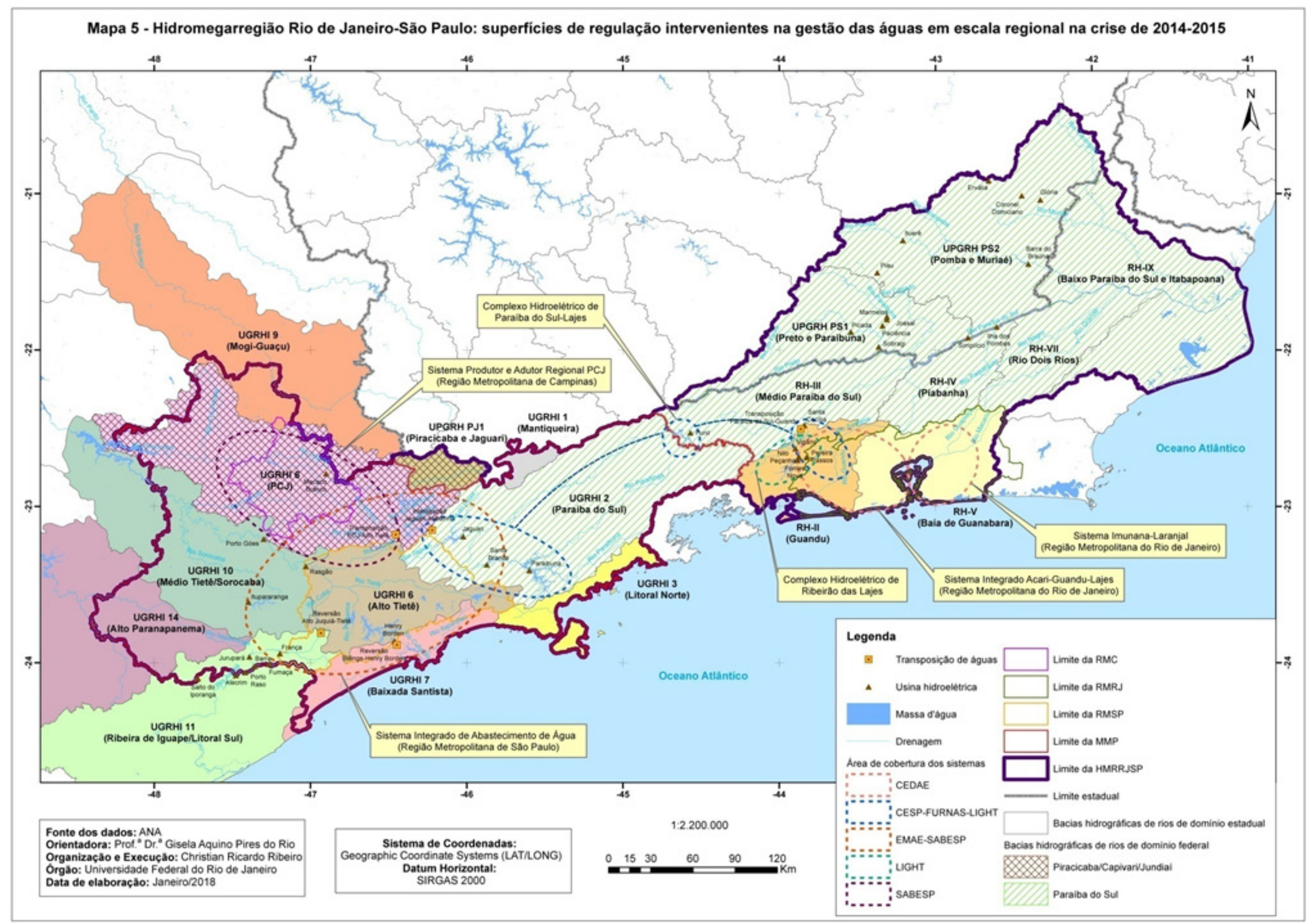


O Mapa 5 expressa a constituição de uma vasta unidade espacial, formada pela unificação de um conjunto de subunidades (sub-regiões) não homogêneas, por meio de estratégias de "salto de escalas", mas também evidencia as relações e as articulações desenvolvidas entre as diversas escalas envolvidas no abastecimento de água das duas regiões metropolitanas. Logo, se admitirmos que as escalas não são imutáveis ou totalmente naturais, mas sim produtos sistêmicos das mudanças tecnológicas, das formas de organização dos seres humanos e das lutas políticas (HARVEY, 2004 [2000]); ou que as diferentes escalas não são pré-existentes, mas constituem e são constituídas através de uma estrutura históricogeográfica de interações sociais (MARSTON, 2004), a hidromegarregião pode ser entendida como o resultado da atuação de múltiplos atores no tempo e no espaço, visando construir interações e conexões sistêmicas de uma maneira intencional, circunscritos por superfícies de regulação associadas a uma lógica espacial areal (bacias e malhas) e/ou reticular (redes).

A emergência da hidromegarregião como uma nova espacialidade é a expressão de uma política de escalas (politics of scale) por meio da qual as diversas escalas intervenientes na gestão das águas são socialmente (re)construídas, refletindo "a articulação de ações e agentes operando em níveis escalares diferentes (isto é, que possuem magnitudes e alcances distintos) com a finalidade de potencializar efeitos, neutralizar ou diminuir o impacto de ações adversas ou tirar maiores vantagens de situações favoráveis" (SOUZA, 2010, p. 42). A política de escalas que sustentou a formação da hidromegarregião reforça a contestação da concepção predominante das escalas geográficas como unidades de área, evidenciando a metáfora das redes de interação como a mais apropriada à compreensão de sua espacialidade (COX, 1998). As alianças e as tensões estabelecidas entre o governo federal e os governos estaduais, que centralizaram a gestão da crise por meio da atuação dos respectivos órgãos gestores de recursos hídricos e das companhias estaduais de saneamento básico, estas últimas responsáveis pela operação das redes de abastecimento, expressam uma política de escalas que possibilitou a construção de uma escala regional de gestão das águas.

\section{Considerações finais}

A crise de abastecimento de água evidenciou o processo de construção de uma escala regional de gestão das águas, gerador de tensões e de conflitos; mediado pela densificação, pela expansão e pela integração crescentes entre os sistemas técnicos de infraestrutura de abastecimento de água; e cujas origens remontam às mudanças ocorridas na organização do espaço das duas maiores metrópoles brasileiras - Rio de Janeiro e São Paulo - e das bacias hidrográficas de seus principais mananciais de abastecimento de água - Rio Paraíba do Sul e Sistema Cantareira, respectivamente. Esse processo deve ser compreendido sob a ótica da dimensão política da regulação, na medida em que a crise evidenciou as lacunas do arranjo institucional e do marco regulatório de gestão das águas atualmente em vigor, mas representa igualmente um turning point em relação às mudanças espaciais que estavam historicamente em curso.

A crise conduziu - ou apenas evidenciou - a um movimento de centralização na gestão dos recursos hídricos. Os órgãos colegiados (CBHs, CERHs e CNRH), instâncias de descentralização e de participação, por excelência, do SINGREH, tiveram um papel de pouca relevância na gestão da crise. As negociações visando atender às demandas das partes interessadas e dirimir as tensões emergentes envolveram basicamente 0 governo federal e os governos estaduais, que também foram os protagonistas na implementação de ações e de medidas de gestão da crise por meio da atuação dos respectivos órgãos gestores de recursos hídricos e das companhias de abastecimento de água. Portanto, a capacidade de resposta do modelo de gestão instituído pela PNRH demonstrou-se incompatível àquela requerida pela conjuntura de crise, seja pela pouca agilidade, seja pela transferência da tomada de decisão para esferas do poder público e para escalas de articulação territorial distintas daquelas representadas pelos $\mathrm{CBHs}$.

A associação entre dois sistemas de gestão complementares, mas estabelecidos a partir de referências territoriais distintas e aparentemente antagônicas - a organização institucional da gestão de recursos hídricos, baseada na atuação de órgãos colegiados no âmbito da unidade natural representada pela bacia hidrográfica, e os sistemas técnicos de infraestrutura de abastecimento de água, que se expandem, se adensam e se integram continuamente por meio da implantação de redes e de transposições respalda a hipótese de que a gestão das águas projetase na escala regional, expressa na formação de uma megarregião hídrica que circunscreve as tensões, as disputas e os conflitos, mas também as alianças e a cooperação estabelecidas entre os atores intervenientes na apropriação dos recursos hídricos e no controle dos fluxos de água que garantem o aprovisionamento dos aglomerados metropolitanos do Rio de Janeiro e de São Paulo. 


\section{Referências}

AMIN, A.; THRIFT, N. (1993). Globalization, institutional thickness and local prospects. In: Revue d'Économie Régionale et Urbaine. Bordeaux: Université Montesquieu-Bordeaux IV, vol. 3, p. 405-427.

BARCELOS, E. A. da S.; WANDERLEY, L. J.; ROCHA-LEÃO, O. M. da; ALENTEJANO, P.; COSTA, P. D’A. (2014). Barragem do Guapiaçu: uma necessidade diante da "crise hídrica" ou mais um negócio suspeito?. In: Terra Livre. São Paulo: Associação dos Geógrafos Brasileiros, ano 30, vol. 2, n.o 42, p. 183-204.

BRITTO, A. L. N. de P. (2015). A gestão do saneamento ambiental: entre o mercado e o direito. In: RIBEIRO, L. C. de Q. Rio de Janeiro: transformações na ordem urbana. Rio de Janeiro: Letra Capital/Observatório das Metrópoles, p. 484-514.

BRITTO, A. L. N. de P.; FORMIGA-JOHNSSON, R. M. F.; CARNEIRO, P. R. F. (2016). Abastecimento público e escassez hidrossocial na Metrópole do Rio de Janeiro. In: Ambiente \& Sociedade. São Paulo: Associação Nacional de PósGraduação e Pesquisa em Ambiente e Sociedade, jan./mar., vol. 19, n.o 1, p. 185-208.

CARMO, R. L. do. (2001). A água é o limite? Redistribuição espacial da população e recursos hídricos no Estado de São Paulo. 2001. 194 f. Tese (Doutorado em Demografia) - Instituto de Filosofia e Ciências Humanas, Universidade Estadual de Campinas, Campinas.

CASTRO, C. M. de. (2010). Águas do Rio de Janeiro: da metrópole com riscos à metrópole dos riscos. 2010. 165 f. Tese (Doutorado em Geografia) - Instituto de Geociências, Universidade Federal do Rio de Janeiro, Rio de Janeiro.

COHIDRO CONSULTORIA, ESTUDOS E PROJETOS. (2014). Plano Integrado de Recursos Hídricos da Bacia Hidrográfica do Rio Paraíba do Sul e Planos de Ação de Recursos Hídricos das Bacias Afluentes. Relatório de Diagnóstico (RP-06 Tomo I). Resende: Associação Pró-gestão das Águas da Bacia Hidrográfica do Rio Paraíba do Sul/Comitê de Integração da Bacia Hidrográfica do Rio Paraíba do Sul.

COMPANHIA BRASILEIRA DE PROJETOS E EMPREENDIMENTOS. (2010). Plano das Bacias Hidrográficas dos Rios Piracicaba, Capivari e Jundiaí 2010-2020: Relatório Final (R8). São Paulo: Comitês das Bacias Hidrográficas dos Rios Piracicaba, Capivari e Jundiaí/Consórcio Intermunicipal das Bacias Hidrográficas dos Rios Piracicaba, Capivari e Jundiaí.

COMPANHIA BRASILEIRA DE PROJETOS E EMPREENDIMENTOS. (2013). Plano Diretor de Aproveitamento de Recursos Hídricos para a Macrometrópole Paulista: Sumário Executivo. São Paulo: Governo do Estado de São Paulo/Secretaria de Estado de Saneamento e Recursos Hídricos/Departamento de Águas e Energia Elétrica.

COORDENAÇÃO DE PROJETOS, PESQUISAS E ESTUDOS TECNOLÓGICOS. (2014). Elaboração do Plano Estadual de Recursos Hídricos do Estado do Rio de Janeiro: Relatório R8 (Cenário Econômico e Demográfico) e Relatório R8-B (Cenários de Demanda e Balanço Hídrico). Rio de Janeiro: Governo do Estado do Rio de Janeiro/Secretaria de Estado do Ambiente/Instituto Estadual do Ambiente.

COX, K. (1998). Spaces of dependence, spaces of engagement and the politics of scale, or: looking for local politics. In: Political Geography. Londres: Elsevier, vol. 17, n.o 1, p. 01-23.

DAVIDOVICH, F. (2001). Metrópole e território: metropolização do espaço no Rio de Janeiro. In: Cadernos Metrópole. Rio de Janeiro: Observatório das Metrópoles, jul./dez., n.o 6, p. 66-77.

EMPRESA PAULISTA DE PLANEJA MENTO METROPOLITANO. (2015). Plano de Ação da Macrometrópole Paulista 20132040: uma visão da Macrometrópole (2). São Paulo: Governo do Estado de São Paulo/Secretaria de Estado da Casa Civil/Empresa Paulista de Planejamento Metropolitano.

FORMIGA-JOHNSSON, R. M.; FARIAS JÚNIOR, J. E. F. de; COSTA, L. F. da; ACSELRAD, M. V. (2015). Segurança hídrica do Estado do Rio de Janeiro face à transposição paulista de águas da Bacia do Paraíba do Sul: relato de um acordo federativo. In: Revista Ineana. Rio de Janeiro: Instituto Estadual do Ambiente, jul./dez., vol. 03, n.o 1, p. 48-82.

FRACALANZA, A. P.; CAMPOS, V. N. de O. (2006). Produção social do espaço urbano e conflitos pela água na Região Metropolitana de São Paulo. In: São Paulo em Perspectiva. São Paulo: Fundação Sistema Estadual de Análise de Dados, abr./jun., vol. 20, n.o 2, p. 32-45.

FUNDAÇÃO DE APOIO À UNIVERSIDADE DE SÃO PAULO. (2009). Plano da Bacia Hidrográfica do Alto Tietê: Relatório Final. São Paulo: Comitê da Bacia Hidrográfica do Alto Tietê. Volume 1/4.

GUSMÃO, P. P. de. (2009). Gestão ambiental do território e capacidade de resposta dos governos locais na área metropolitana do Rio de Janeiro. In: BICALHO, A. M. S. M.; GOMES, P. C. da C. (Org.). Questões metodológicas e novas temáticas na pesquisa geográfica. Rio de Janeiro: Publit/Coordenação de Aperfeiçoamento de Pessoal de Nível Superior/Programa de Pós-Graduação em Geografia da Universidade Federal do Rio de Janeiro, p. 163-184.

HARVEY, D. (2004 [2000]). Espaços de esperança. 3.a ed. São Paulo: Loyola.

INSTITUTO BRASILEIRO DE GEOGRAFIA E ESTATÍSTICA. Censo Demográfico 2010: Principais resultados: Tabelas: Regiões Metropolitanas. Disponível em: <https://www.ibge.gov.br/estatisticas/sociais/populacao/9662-censo- 
demografico-2010.html?=\& t=resultados>. Acesso em: 20 jan. 2018.

LENCIONI, S. (2011). A metamorfose de São Paulo: o anúncio de um novo mundo de aglomerações difusas. In: Revista Paranaense de Desenvolvimento. Curitiba: Instituto Paranaense de Desenvolvimento, jan./jun., n.o 120, p. 133-148.

(2015). Metropolização do espaço e a constituição de megarregiões. In: FERREIRA, A.; RUA, J.; MATTOS, R. C. de. (Org.). Desafios da metropolização do espaço. Rio de Janeiro: Conseqüência, p. 35-68.

MAGALHÃES, F. N. C. (2008). Da metrópole à cidade-região: na direção de um novo arranjo espacial metropolitano?. In: Revista Brasileira de Estudos Urbanos e Regionais. Rio de Janeiro: Associação Nacional de Pós-Graduação e Pesquisa em Planejamento Urbano e Regional, nov., vol. 10, n.o 2, p. 09-27.

MARSTON, S. (2004). A long way from home: domesticating the social production of scale. In: SHEPPARD, E.; McMASTER, R. B. (Org.). Scale and geographic inquiry: nature, society, and method. Oxford, Blackwell, p. 170-191.

PIRES DO RIO, G. A. (2008). Gestão de Águas: um desafio geoinstitucional. In: OLIVEIRA, M. P. de; COELHO, M. C. N.; CORRÊA, A. de M. (Org.). O Brasil, a América Latina e o mundo: espacialidades contemporâneas (I). Rio de Janeiro: Lamparina/Associação Nacional de Pós-Graduação e Pesquisa em Geografia/Fundação Carlos Chagas Filho de Amparo à Pesquisa do Estado do Rio de Janeiro, p. 220-236.

(2009). Território, instituições e superfícies de regulação. In: BICALHO, A. M. de S. M.; GOMES, P. C. da C. (Org.). Questões metodológicas e novas temáticas na pesquisa geográfica. Rio de Janeiro: Publit/Coordenação de Aperfeiçoamento de Pessoal de Nível Superior/Programa de Pós-Graduação em Geografia da Universidade Federal do Rio de Janeiro, p. 27-44.

(2017). Bacia do Paraíba do Sul: a tomada de uma crise de abastecimento de água. In: ASSOCIAÇÃO NACIONAL DE PÓS-GRADUAÇÃO E PESQUISA EM PLANEJAMENTO URBANO E REGIONAL, 17, 2017, São Paulo. Anais eletrônicos... São Paulo: Associação Nacional de Pós-Graduação e Pesquisa em Planejamento Urbano e Regional, p. 01-11.

PIRES DO RIO. G. A.; DRUMMOND, H. R.; RIBEIRO, C. R. (2016). Água: urgência de uma agenda territorial. In: Ambiente \& Sociedade. São Paulo: Associação Nacional de Pós-Graduação e Pesquisa em Ambiente e Sociedade, out./dez., vol. 19, n.o 4, p. 105-120.

PIRES DO RIO, G. A.; FRACALANZA, A. P.; SOUZA, N. R. de; CARMO, R, L. do. (2011). Política Nacional de Gestão de Águas: há lugar para as cidades-região?. In: SIMPÓSIO NACIONAL DE GEOGRAFIA URBANA, 12, 2011, Belo Horizonte. Anais eletrônicos... Belo Horizonte: Universidade Federal de Minas Gerais, p. 01-13.

PIRES DO RIO, G. A.; PEIXOTO, M. N. de O. (2001). Superfícies de regulação e conflitos de atribuições na gestão de recursos hídricos. In: Território. Rio de Janeiro: Universidade Federal do Rio de Janeiro, jan./jun., ano 6, n.o 10, p. 51-65. RIBEIRO, L. C. de Q.; SILVA, E. T. da; RODRIGUES, J. M. (2011). Metrópoles brasileiras: diversificação, concentração e dispersão. In: Revista Paranaense de Desenvolvimento. Curitiba: Instituto Paranaense de Desenvolvimento, jan./jun., n.o 120, p. 177-207.

SCOTT, A.; AGNEW, J.; SOJA, E.; STORPER, M. (2001). Cidades-regiões globais. In: Espaço \& Debates. São Paulo: Universidade de São Paulo, ano 18, n.o 41, p. 11-25.

SILVA, A. C. P. da. (2016). Uma trajetória de investigação de Geografia Política na Região Metropolitana do Rio de Janeiro. In: GEOgraphia. Rio de Janeiro: Universidade Federal Fluminense, ano 18, n.o 37, p. 95-114.

SILVA, R. T. (2011). Integration of hydraulic infrastructure in Metropolitan São Paulo. Prospects of change in a context of growing vulnerability. In: Geographica Helvetica. Göttingen: Copernicus, vol. 66, n.o 2, p. 92-99.

(2015). Águas e saneamento na Macrometrópole Paulista: o desafio da integração de escopos. In: Revista Iberoamericana de Urbanismo. Barcelona/Buenos Aires/Palma de Mallorca: Universitat Politècnica de Catalunya, dez., ano 7, n.o 12, p. 137-156.

SILVA, A. P. da; OLIVEIRA, E. F. de; CONSOLI, M. A. F. (2009). Aspectos críticos da poluição da Bacia do Rio Guandu: sua influência sobre a ETA Guandu e o abastecimento da população da Cidade do Rio de Janeiro. In: SIMPÓSIO BRASILEIRO DE RECURSOS HÍDRICOS, 18, 2009, Campo Grande. Anais eletrônicos... Campo Grande: Associação Brasileira de Recursos Hídricos, p. 01-18.

SMITH, N. (2004). Scale bending and the fate of the national. In: SHEPPARD, E.; McMASTER, R. B. (Org.). Scale and geographic inquiry: nature, society, and method. Oxford: Blackwell, p. 192-212.

SONDOTÉCNICA ENGENHARIA DE SOLOS. (2006). Plano Estratégico de Recursos Hídricos da Bacia Hidrográfica dos Rios Guandu, da Guarda e Guandu-Mirim: Relatório do Diagnóstico (Final). Brasília: Agência Nacional de Águas. Volumes 1 e 2 .

SOUZA, M. L. de. (2010). Com o Estado, apesar do Estado, contra o Estado: os movimentos urbanos e suas práticas espaciais, entre a luta institucional e a ação direta. In: Cidades. Presidente Prudente: Universidade Estadual Paulista, vol. 7, n.o 11, p. 13-47. 